\title{
Diabetes Mellitus and Increased Tuberculosis Susceptibility: The Role of Short-Chain Fatty Acids
}

\author{
Ekta Lachmandas, Corina N. A. M. van den Heuvel, Michelle S. M. A. Damen, \\ Maartje C. P. Cleophas, Mihai G. Netea, and Reinout van Crevel
}

Department of Internal Medicine and Radboudumc Center for Infectious Diseases, Radboud University Medical Center, Internal Postal Code 463, P.O. Box 9101, 6500 HB Nijmegen, Netherlands

Correspondence should be addressed to Ekta Lachmandas; ekta.lachmandas@radboudumc.nl

Received 17 July 2015; Accepted 18 October 2015

Academic Editor: Francisco J. Ruperez

Copyright ( 2016 Ekta Lachmandas et al. This is an open access article distributed under the Creative Commons Attribution License, which permits unrestricted use, distribution, and reproduction in any medium, provided the original work is properly cited.

\begin{abstract}
Type 2 diabetes mellitus confers a threefold increased risk for tuberculosis, but the underlying immunological mechanisms are still largely unknown. Possible mediators of this increased susceptibility are short-chain fatty acids, levels of which have been shown to be altered in individuals with diabetes. We examined the influence of physiological concentrations of butyrate on cytokine responses to Mycobacterium tuberculosis (Mtb) in human peripheral blood mononuclear cells (PBMCs). Butyrate decreased Mtb-induced proinflammatory cytokine responses, while it increased production of IL-10. This anti-inflammatory effect was independent of butyrate's well-characterised inhibition of HDAC activity and was not accompanied by changes in Toll-like receptor signalling pathways, the eicosanoid pathway, or cellular metabolism. In contrast blocking IL-10 activity reversed the effects of butyrate on Mtbinduced inflammation. Alteration of the gut microbiota, thereby increasing butyrate concentrations, can reduce insulin resistance and obesity, but further studies are needed to determine how this affects susceptibility to tuberculosis.
\end{abstract}

\section{Introduction}

Tuberculosis (TB) is the second leading cause of death from an infectious disease worldwide [1]. Susceptibility to TB can be increased by several comorbidities, one of which is type 2 diabetes mellitus (DM) [2]. DM patients present with an overall threefold increased risk of developing active TB [3]. Globally, $15 \%$ of TB cases are estimated to be attributable to DM [4] and thus with a predicted increase of DM by $155 \%$ over the next 20 years, DM will become an increasingly important factor challenging TB control [5-7].

DM patients exhibit alterations in the immune response against Mycobacterium tuberculosis (Mtb), making them more susceptible to infection or progression towards active TB disease and less responsive to treatment [8-11]. However, the underlying biological mechanisms remain largely unknown $[12,13]$. DM patients have been associated with dysregulated cytokine responses to $\mathrm{Mtb}$ [14-17]. Whilst proinflammatory cytokines are necessary for protection against $\mathrm{Mtb}$, anti-inflammatory cytokines may counteract these effects.
Possible factors that may impact the host response in patients with DM are short-chain fatty acids (SCFAs), the main metabolic products of fermentation of nondigestible dietary fibres by the gut microbiota. Numerous reports have demonstrated that DM patients present with an altered composition of their gut microbiota, which subsequently alters their SCFA levels [18-24]. SCFAs strongly modulate immune and inflammatory responses [22, 25-31], thereby influencing the host response to Mtb. SCFAs, of which butyrate (C4) is the most thoroughly studied, act on immune and endothelial cells via at least two mechanisms: activation of G-protein coupled receptors (GPCRs) and inhibition of histone deacetylase (HDAC) [32]. They affect the function of various cell types such as lymphocytes [33, 34], neutrophils $[25,31,35]$, and macrophages [28, 36-38]. In light of the emerging role of the microbiota in inflammation and immunity, we hypothesized that SCFAs, and in particular butyrate, may affect the immune response and susceptibility to Mtb in type 2 DM patients.

In this study we investigated the role of physiological concentrations of SCFAs on the cytokine response against 
Mtb in human peripheral blood mononuclear cells (PBMCs). We subsequently examined a number of possible mechanisms via which altered concentrations of one particular SCFA, C4, might affect the host immune response to Mtb in DM patients. To this purpose, we studied the influence of physiological concentrations of C4 on HDAC activity, immune signalling pathways, the eicosanoid pathway, and cellular metabolism. To our knowledge, this is the first study reporting on the effects of physiological plasma concentrations of $\mathrm{C} 4$ on Mtb-induced cellular responses. Physiological plasma concentrations of $\mathrm{C} 4$ are in the micromolar range [39], whilst in previous studies $\mathrm{C} 4$ has been used in the millimolar range. Thus, this study substantially adds to our knowledge of SCFAs as possible mediators of altered immune responses to $\mathrm{Mtb}$ in DM patients.

\section{Materials and Methods}

2.1. Human Samples. PBMCs were isolated from buffy coats donated after written informed consent by healthy volunteers to the Sanquin Blood Bank (http://www.sanquin.nl/en/) in Nijmegen. Experiments were conducted according to the principles expressed in the Declaration of Helsinki. Since blood donations were anonymous no tuberculosis skin test or IFN- $\gamma$ release assay was performed. However, the incidence of TB in the Dutch population is extremely low $(4 / 100,000)$, and Bacillus Calmette-Guérin (BCG) vaccination is not part of the routine vaccination program. Blood donors were not screened for DM as prevalence of DM among people under 45 years of age (median age of blood donors) is about $1.5 \%$ and therefore DM is unlikely to be a confounding factor [34].

2.2. H37Rv Lysates and Culture. $\mathrm{H} 37 \mathrm{Rv} \mathrm{Mtb}$ was grown to mid-log phase in Middlebrook 7H9 liquid medium (Difco, Becton Dickinson) supplemented with oleic acid/albumin/ dextrose/catalase (OADC) (BBL, Becton Dickinson), washed three times in sterile saline, heat killed, and then disrupted using a bead beater, after which the concentration was measured using a bicinchoninic acid (BCA) assay (Pierce, Thermo Scientific).

2.3. Cell Stimulation Experiments. Isolation of PBMCs was performed by differential centrifugation over Ficoll-Paque (GE Healthcare). Cells were adjusted to $5 \times 10^{6}$ cells $/ \mathrm{mL}$ (Beckman Coulter) and suspended in RPMI 1640 (Gibco) supplemented with $10 \mu \mathrm{g} / \mathrm{mL}$ gentamicin (Lonza), $10 \mathrm{mM} \mathrm{L-}$ glutamine (Life Technologies), and $10 \mathrm{mM}$ pyruvate (Life Technologies). $100 \mu \mathrm{L}$ of PBMCs was incubated in roundbottom 96-well plates (Greiner), pretreated with SCFAs for $1 \mathrm{~h}$, and stimulated with $1 \mu \mathrm{g} / \mathrm{mL}$ of $\mathrm{H} 37 \mathrm{Rv}$ lysate or $10 \mathrm{ng} / \mathrm{mL}$ LPS (Sigma-Aldrich, E. coli serotype 055:B5). Cells were incubated for $24 \mathrm{~h}$ or 7 days at $37^{\circ} \mathrm{C}$ in a $5 \% \mathrm{CO}_{2}$ environment ( $n=6$ to 11). Alternatively, PBMCs were pretreated for 1 hour $\left(37^{\circ} \mathrm{C}, 5 \% \mathrm{CO}_{2}\right)$ with ranolazine (ITK Diagnostics), trimetazidine (Sigma), pertussis toxin (Enzo Life Sciences), etomoxir (Sigma) (inhibitors of $\beta$-oxidation, $n=3$ ), aspirin (Aspégic injection powder, $n=3$ ), cycloheximide (Sigma, $n=6$ to 7 ), anti-IL-10 antibody IgG2a (BioLegend, $n=10$ to 12 ), or IgG2a isotype control (BioLegend, $n=10$ to 12 ) prior to stimulation. Cell culture supernatants were collected and stored at $-20^{\circ} \mathrm{C}$ for cytokine measurements, performed by ELISA: TNF- $\alpha$, IL-1 $\beta$, IL-17A, IL-22, and IL-1Ra (R\&D Systems) and IL-6, IFN- $\gamma$, and IL-10 (Sanquin).

2.4. Quantification of Gene Expression. For quantitative realtime PCR (qPCR) analysis RNA was isolated from PBMCs using TRIzol reagent (Invitrogen Life Technologies) according to the manufacturer's protocol. RNA was transcribed into complementary DNA (cDNA) by reverse transcription using iScript cDNA synthesis kit (Bio-Rad, Hercules, CA). Primer sequences (Biolegio) are given in Table 1. Power SYBR Green PCR Master Mix (Applied Biosystems) was used for qPCR on an AB StepOnePlus real-time PCR system (Applied Biosystems). qPCR data were normalized to the housekeeping gene human $\beta 2 \mathrm{M}$ ( $n=3$ to 10$)$.

2.5. Protein Phosphorylation Measurements. Western blotting was carried out using a Trans-Blot Turbo system (Bio-Rad) according to manufacturer's instructions. $5 \times 10^{6}$ PBMCs were lysed in $100 \mu \mathrm{L}$ lysis buffer. The resulting lysate was used for Western blot analysis. Equal amounts of protein were separated by SDS-PAGE on 4-15\% polyacrylamide gels (BioRad) and transferred to PVDF (Bio-Rad) membranes. Membranes were blocked for $1 \mathrm{~h}$ and then incubated overnight with primary antibody (dilution $1: 1000$ ) in $5 \%(\mathrm{w} / \mathrm{v}) \mathrm{BSA}$ or milk in TBS-Tween buffer (TBS-T). Blots were washed in TBS-T 3 times and incubated with HRP-conjugated antirabbit antibody (1:5000; Sigma) in 5\% (w/v) milk in TBS$\mathrm{T}$ for $1 \mathrm{~h}$ at room temperature (RT). After washing, blots were developed with ECL (Bio-Rad) following manufacturer's instructions. Primary antibodies used were rabbit anti-p38 MAPK, rabbit anti-phospho-p38 MAPK, rabbit anti-ERK1/2 (p44/p42 MAPK), rabbit anti-phospho-ERK1/2 (P44/42 MAPK, T202/Y204), and rabbit anti-phospho-JNK (T183/Y185) (all Cell Signalling) $(n=2)$.

2.6. Metabolite Measurements. Lactate was measured from cell culture supernatants using a coupled enzymatic assay in which lactate was oxidised and the resulting $\mathrm{H}_{2} \mathrm{O}_{2}$ was coupled to the conversion of Amplex Red reagent to fluorescent resorufin by HRP (horseradish peroxidase). $30 \mu \mathrm{L}$ of lactate standard or $200 \mathrm{x}$ diluted sample was added to $30 \mu \mathrm{L}$ of reaction mix. The $30 \mu \mathrm{L}$ of reaction mix consisted of $0.6 \mu \mathrm{L}$ of $10 \mathrm{U} / \mathrm{mL}$ HRP (Sigma), $0.6 \mu \mathrm{L}$ of $100 \mathrm{U} / \mathrm{mL}$ lactate oxidase (Sigma), $0.3 \mu \mathrm{L}$ of $10 \mathrm{mM}$ Amplex Red reagent (Life Technologies), and $28.5 \mu \mathrm{L}$ PBS. Samples were incubated for $20 \mathrm{~min}$ at RT and fluorescence (excitation/emission maxima $=570 / 585 \mathrm{~nm}$ ) was measured on an ELISA reader (BioTek) $(n=3$ to 5$)$.

Measurements of the $\mathrm{NAD}^{+} / \mathrm{NADH}$ redox ratio were adapted from Zhu and Rand [40]. Briefly, 1.5 million stimulated PBMCs were lysed in $75 \mu \mathrm{L}$ of homogenization buffer (10 mM nicotinamide (Sigma), $10 \mathrm{mM}$ Tris-Cl (Sigma), and $0.05 \%(\mathrm{w} / \mathrm{v}$ ) Triton X-100 (Sigma), pH 7.4). The lysate was centrifuged at $12000 \mathrm{~g}$ for $1 \mathrm{~min}$. From the resulting supernatants two $18 \mu \mathrm{L}$ aliquots were removed and either 
TABLE 1: Primer sequences used for gene expression measurements by qPCR.

\begin{tabular}{|c|c|c|}
\hline Target & Forward $5^{\prime} \rightarrow 3^{\prime}$ & Reverse $5^{\prime} \rightarrow 3^{\prime}$ \\
\hline h- $\beta 2 \mathrm{M}$ & ATGAGTATGCCTGCCGTGTG & CCAAATGCGGCATCTTCAAAC \\
\hline h-COX-2 & CTGGCGCTCAGCCATACAG & CGCACTTATACTGGTCAAATCCC \\
\hline h-CS & GGTGGCATGAGAGGCATGAA & TAGCCTTGGGTAGCAGTTTCT \\
\hline h-HDAC1 & CCGCATGACTCATAATTTGCTG & ATTGGCTTTGTGAGGGCGATA \\
\hline h-HDAC8 & TCGCTGGTCCCGGTTTATATC & TACTGGCCCGTTTGGGGAT \\
\hline h-HIF1- $\alpha$ & GAACGTCGAAAAGAAAAGTCTCG & CCTTATCAAGATGCGAACTCACA \\
\hline h-IDH2 & CGCCACTATGCCGACAAAAG & ACTGCCAGATAATACGGGTCA \\
\hline h-IL-10 & CAACCTGCCTAACATGCTTCG & TCATCTCAGACAAGGCTTGGC \\
\hline h-IL-1 $\beta$ & GCCCTAAACAGATGAAGTGCTC & GAACCAGCATCTTCCTCAG \\
\hline h-IL12p35 & ССTTGCACTTCTGAAGAGATTGA & ACAGGGCCATCATAAAAGAGGT \\
\hline h-IL23p19 & CTCAGGGACAACAGTCAGTTC & ACAGGGCTATCAGGGAGC \\
\hline h-MDH2 & TCGGCCCAGAACAATGCTAAA & GCGGCTTTGGTCTCGATGT \\
\hline h-SOCS1 & TTTTCGCCCTTAGCGTGAAGA & GAGGCAGTCGAAGCTCTCG \\
\hline h-SOCS3 & TGCGCCTCAAGACCTTCAG & GAGCTGTCGCGGATCAGAAA \\
\hline h-ST2 & TTGTCTACCCACGGAACTACA & GCTCTTTCGTATGTTGGTTTCCA \\
\hline h-TNF- $\alpha$ & ССТСТСТСТААТСАGСССТСТG & GAGGACCTGGGAGTAGATGAG \\
\hline h-Tollip & TGGGCCGACTGAACATCAC & GTGGATGACCTTATTCCAGCG \\
\hline
\end{tabular}

$2 \mu \mathrm{L}$ of $0.2 \mathrm{M} \mathrm{HCl}$ or $0.2 \mathrm{M} \mathrm{NaOH}$ was added to each aliquot. The samples were heated for $30 \mathrm{~min}$ at $65^{\circ} \mathrm{C}$ and after incubation $2 \mu \mathrm{L}$ of opposite reagent $(\mathrm{NaOH}$ or $\mathrm{HCl})$ was added to each aliquot. $5 \mu \mathrm{L}$ of sample or $\operatorname{NAD}^{+}(\beta-$ nicotinamide adenine dinucleotide hydrate; Sigma) standard was then mixed with $85 \mu \mathrm{L}$ of reaction mix and $60 \mu \mathrm{L}$ of fluorescence mix in a black 96 -well plate. The reaction mix consisted of $100 \mathrm{mM}$ bicine (N,N-bis(2-hydroxyethyl)glycine; Sigma), 0.6 mM ethanol (Sigma), and $5 \mathrm{mM}$ EDTA (Life Technologies). The fluorescence mix consisted of $0.5 \mathrm{mM}$ PMS (phenazine methosulfate; Sigma), $0.05 \mathrm{mM}$ resazurin (Sigma), and $0.2 \mathrm{mg}$ of ADH (alcohol dehydrogenase; Sigma). The reaction was incubated for $15 \mathrm{~min}$ at RT and fluorescence (excitation/emission maxima $=540 / 586 \mathrm{~nm})$ was measured on an ELISA reader (BioTek) ( $n=3$ to 5$)$.

2.7. HDAC Activity Assay. HDAC Fluorometric Cellular Activity Assay BML-AK503 (FLUOR DE LYS, Enzo Life Sciences, Inc., Farmingdale, NY) was used to determine HDAC activity in PBMCs pretreated with C4 (30 min) and then stimulated with H37Rv (30 min). Subsequently PBMCs were incubated with acetylated substrate for 2 hours, after which a developer was added to generate a fluorescent signal from the deacetylated substrate. Fluorescence was measured on a microplate reader (BioTek). Trichostatin A (TSA) was used as a positive control for HDAC inhibition $(n=5$ to 6$)$.

2.8. Flow Cytometry. PBMCs were treated with $50 \mu \mathrm{mol} \mathrm{C4}$ for $1 \mathrm{~h}$ and stimulated with $1 \mu \mathrm{g} / \mathrm{mL} \mathrm{H} 37 \mathrm{Rv}$ or $10 \mathrm{ng} / \mathrm{mL}$ LPS for 7 days. Subsequently cells were restimulated with $200 \mu \mathrm{L}$ RPMI supplemented with $10 \%$ serum, Golgi-plug inhibitor (GPI Brefeldin A; $1 \mu \mathrm{g} / \mathrm{mL}, \mathrm{BD}$ Pharmingen), PMA (phorbol 12-myristate 13-acetate; $50 \mu \mathrm{g} / \mathrm{mL}$, Sigma-Aldrich), and ionomycin $\left(1 \mu \mathrm{g} / \mathrm{mL}\right.$, Sigma-Aldrich) for $4-6 \mathrm{~h}$ at $37^{\circ} \mathrm{C}$ and $5 \% \mathrm{CO}_{2}$. Cells were then washed with PBA (PBS 1\% BSA (albumin from bovine serum)) and stained extracellularly for 30 min with CD4-PeCys7 (ITK) for T-helper 17 (Th17) cells at $4^{\circ} \mathrm{C}$. Next, cells were washed and permeabilized by fix and perm buffer (eBioscience) according to the manufacturer's protocol for $45-60 \mathrm{~min}$ at $4^{\circ} \mathrm{C}$. Finally cells were washed and resuspended in $300 \mu \mathrm{L}$ PBA to be measured using the Cytomics FC500 (Beckman Coulter) $(n=8)$.

Cell death was measured by staining PBMCs with Annexin V-FITC (BioVision) and Propidium Iodide (PI) (Invitrogen Molecular Probes). Cells were incubated in the dark on ice with Annexin-V staining solution (RPMI supplemented with $5 \mathrm{mM} \mathrm{CaCl}_{2}$ and $0.1 \mu \mathrm{L} / \mathrm{mL}$ AnnexinV) for 15 minutes. Subsequently PBMCs were stained with PI for 5 minutes. Cells were measured with the Cytomics FC500 (Beckman Coulter, Woerden, Netherlands), and data were analysed using CXP analysis software v2.2 (Beckman Coulter) ( $n=3$ to 5$)$.

2.9. Statistical Analysis. All data were analysed using a paired nonparametric Wilcoxon signed-rank test, as the data were not normally distributed. Differences were considered statistically significant at $p$ value $<0.05$. Data are shown as cumulative results of levels obtained in all volunteers (means \pm SEM).

\section{Results}

3.1. Short-Chain Fatty Acids Inhibit Mtb-Induced Cytokine Responses. DM is associated with altered gut microbiota and consequently altered SCFA levels [18-22]. In line with current literature [22, 25-31], we hypothesized that SCFAs have the potential to influence the host inflammatory response against Mtb. In particular we investigated the effects of varying doses of acetate (C2), propionate (C3), and butyrate (C4) on $\mathrm{H} 37 \mathrm{Rv}$-induced cytokine responses, with RPMI as negative 
control and LPS as positive control (Figure 1). SCFAs themselves did not induce cytokine production (results not shown) but significantly affected $\mathrm{H} 37 \mathrm{Rv}$-induced cytokine release. C2, C3, and C4 significantly, dose-dependently decreased $\mathrm{H} 37 \mathrm{Rv}$-induced production of proinflammatory cytokines TNF- $\alpha$, IL- $1 \beta$, and IL-17, while nonsignificant effects were found for IL-6, IFN- $\gamma$, and IL-22 production. In contrast, C3 and $\mathrm{C} 4$ induced a significant increase in $\mathrm{H} 37 \mathrm{Rv}$-induced production of the anti-inflammatory cytokine IL-10. Similarly, C3 and C4 but not C2 decreased LPS-induced production of TNF- $\alpha$ and IL- 6 , while the release of IL- $1 \beta$ was significantly decreased in response to all three SCFAs (results not shown). LPS did not induce production of IFN- $\gamma$, IL-17, or IL22. Moreover, all three SCFAs incurred a dose-dependent, nonsignificant decrease in LPS-induced IL-10 production (results not shown).

Overall, C4 resulted in some of the most significant changes in cytokine responses (Figure 1(b)). Moreover, the potency of butyrate in reducing cytokine responses to $\mathrm{H} 37 \mathrm{Rv}$ and LPS was greater than that for the other SCFAs. Importantly, changes in cytokine levels could not be explained by altered $\mathrm{pH}$ levels or cell death (Supplementary Figure $1 \mathrm{~A}$ and $\mathrm{B}$ in Supplementary Material available online at http://dx.doi.org/10.1155/2016/6014631). Therefore, following this screen, we continued our study with $\mathrm{C} 4$ at a concentration of $50 \mu \mathrm{M}$, which is physiologically relevant because it is comparable to human plasma concentrations [39].

\subsection{Influence of Butyrate on HDAC Expression and Activity.} Butyrate is reported to be a strong HDAC inhibitor. Since this might account for its anti-inflammatory effects [41-44], we examined the effect of $\mathrm{C} 4$ on HDAC expression and activity. C4 significantly decreased HDAC8 but not HDAC1 gene expression upon H37Rv stimulation of PBMCs (Figure 2(a)). Consistent with previous reports [36, 42-44], C4 at a high dose of $1 \mathrm{mM}$ decreased HDAC activity upon both RPMI and $\mathrm{H} 37 \mathrm{Rv}$ stimulation. However, different from its effect on gene expression, C4 at a physiological dose of $50 \mu \mathrm{M}$ had no effect on actual HDAC activity (Figure 2(b)), while trichostatin A (TSA, positive control) strongly decreased HDAC activity. These data suggest that butyrate's inhibition of HDAC activity is unlikely to play a role in the effects of low doses of $\mathrm{C} 4$ on $\mathrm{Mtb}$-induced inflammatory responses and stresses the importance of studying the effects of butyrate at physiologically relevant concentrations.

\subsection{The Effects of Butyrate on TLR-Signalling Mediators} and the Eicosanoid Pathway. Signalling of Toll-like receptors (TLRs), important receptors for Mtb recognition [45-47], is controlled by feedback mechanisms regulated by several intracellular kinases [48, 49]. Because impaired Mtb recognition and insufficient TLR signalling may account for the anti-inflammatory effects of $\mathrm{C} 4$, we examined whether $\mathrm{C} 4$ affected these feedback loops. However, C4 had no effect on phosphorylation of the MAP kinases p38, ERK (Figure 3(a)), or JNK (Supplementary Figure 2). C4 has also been reported to induce expression of inhibitors of TLR signalling pathways [50], but we found that C4 significantly decreased mRNA expression of TLR signalling inhibitors SOCS1 and Tollip and did not affect expression of SOCS3 or ST2 (Figure 3(b)). Of note, these results were not explained by cell death (Supplementary Figure $1 \mathrm{~B}$ ).

Aside from TLR signalling, C4 possibly exerts its antiinflammatory effects through modulation of the eicosanoid pathway. Eicosanoids, oxygenated metabolites of arachidonic acid, modulate the host immune response to Mtb [51-55]. $\mathrm{C} 4$ has been reported to upregulate key enzymes of the eicosanoid pathway upon LPS stimulation [30], but a reverse effect has also been described [56]. We did not observe a significant impact of $\mathrm{C} 4$ on transcript levels of cyclooxygenase 2 (COX-2), one of the main eicosanoid enzymes, upon H37Rv or LPS stimulation (Supplementary Figure $3 \mathrm{~A}$ ). Alternatively, $\mathrm{C} 4$ has been described to induce release of the antiinflammatory prostaglandin $\mathrm{PGE}_{2}[26,30,57]$. Inhibition of $\mathrm{PGE}_{2}$ with aspirin could not counteract the inhibitory effects of C4 on TNF- $\alpha$ and IL- $1 \beta$ cytokine responses upon either $\mathrm{H} 37 \mathrm{Rv}$ or LPS stimulation (Supplementary Figure $3 \mathrm{~B}$ ). The eicosanoid pathway is therefore unlikely to be the mediator pathway through which $\mathrm{C} 4$ exerts its anti-inflammatory effects.

\subsection{Influence of Butyrate on Cellular Metabolism. Another} possible explanation for butyrate's anti-inflammatory effects is its influence on cellular metabolism. A recent paper described that microbiota have a strong effect on energy homeostasis in the mammalian colon and showed that C4 regulates different aspects of energy metabolism acting as an important energy source for colonocytes [58]. Contrary to this previous study, we observed no effects of $\mathrm{C} 4$ on cellular lactate production, the $\mathrm{NAD}^{+} / \mathrm{NADH}$ redox ratio, TCA cycle gene expression (Figure 4 ), or $\beta$-oxidation (Supplementary Figure 4 ). These data strongly suggest that $\mathrm{C} 4$ modulates the immune response to $\mathrm{Mtb}$ independently of cellular metabolism.

3.5. Butyrate Transcriptionally Influences Cytokine Responses to Mtb, Possibly Mediated through IL-10 Induction. We next examined whether the inhibitory effect of C4 on Mtbinduced proinflammatory cytokine responses, with a concomitant increase in anti-inflammatory IL-10 production (Figure 1) and decrease in Th17 proliferation (Supplementary Figure $5 \mathrm{~A}$ ), was also present at the level of gene transcription. C4 led to a decrease in TNF- $\alpha$, IL-12, and IL23 mRNA levels upon $\mathrm{H} 37 \mathrm{Rv}$ stimulation and a parallel increase in IL-10 mRNA (Figure 5(a)), while no effect on production of the anti-inflammatory cytokine IL-1Ra was observed (Supplementary Figure $5 \mathrm{~B}$ ). These data point to IL-10 as a possible intermediary mediator of the antiinflammatory effects of $\mathrm{C} 4$. We therefore assessed whether removing IL-10 protein from the cellular environment could counteract the inhibitory effects of $\mathrm{C} 4$. To this end, we pretreated $\mathrm{PBMCs}$ with cycloheximide (CHX), an inhibitor of translation. Stimulation of PBMCs with $\mathrm{H} 37 \mathrm{Rv}$ in the presence of $\mathrm{C} 4$ in combination with $\mathrm{CHX}$ resulted in higher TNF- $\alpha$ responses, as compared to incubation with $\mathrm{H} 37 \mathrm{Rv}$ and C4 alone. Upon LPS stimulation, this effect was not present (Figure 5(b)). We subsequently examined whether 

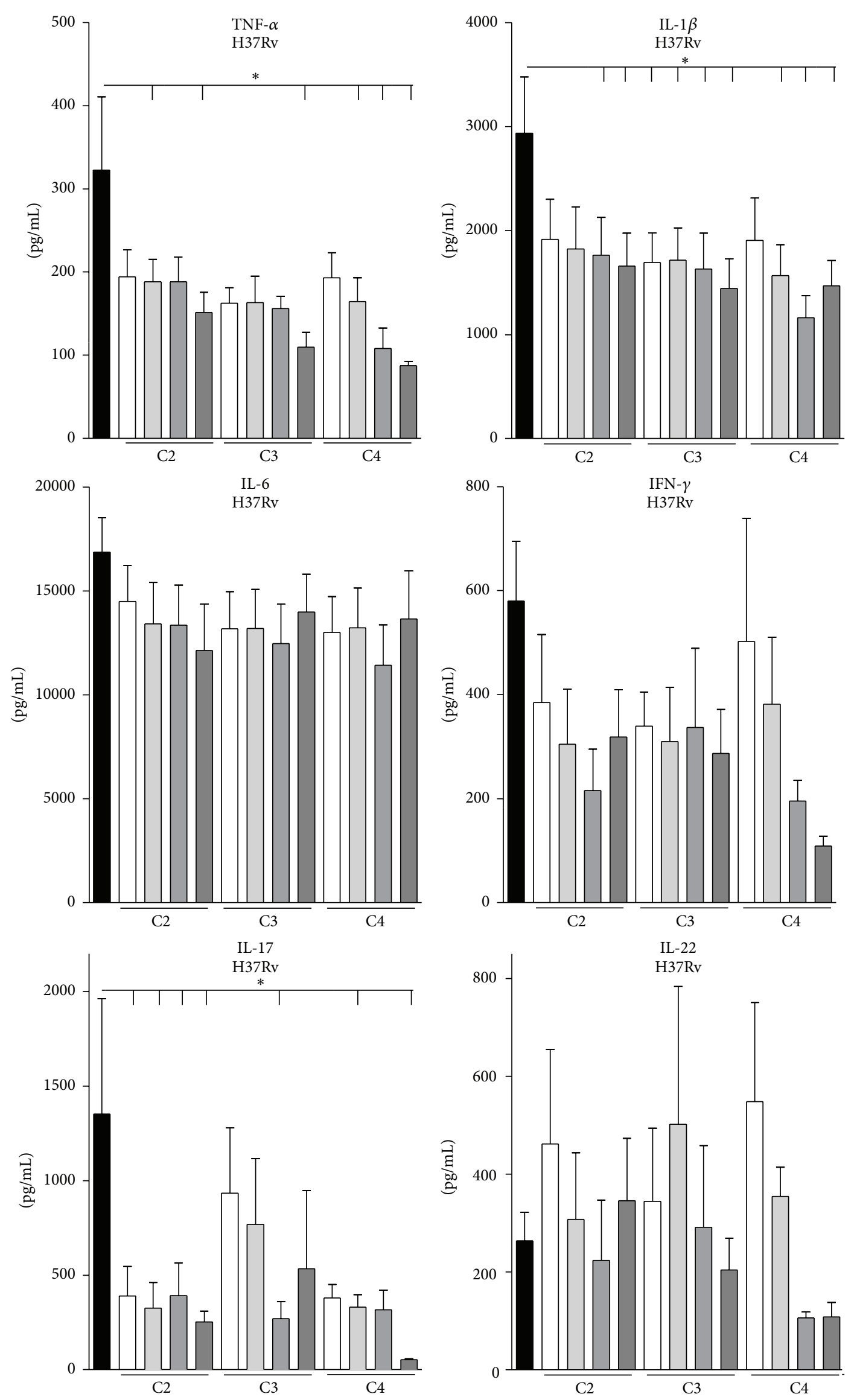

Figure 1: Continued. 


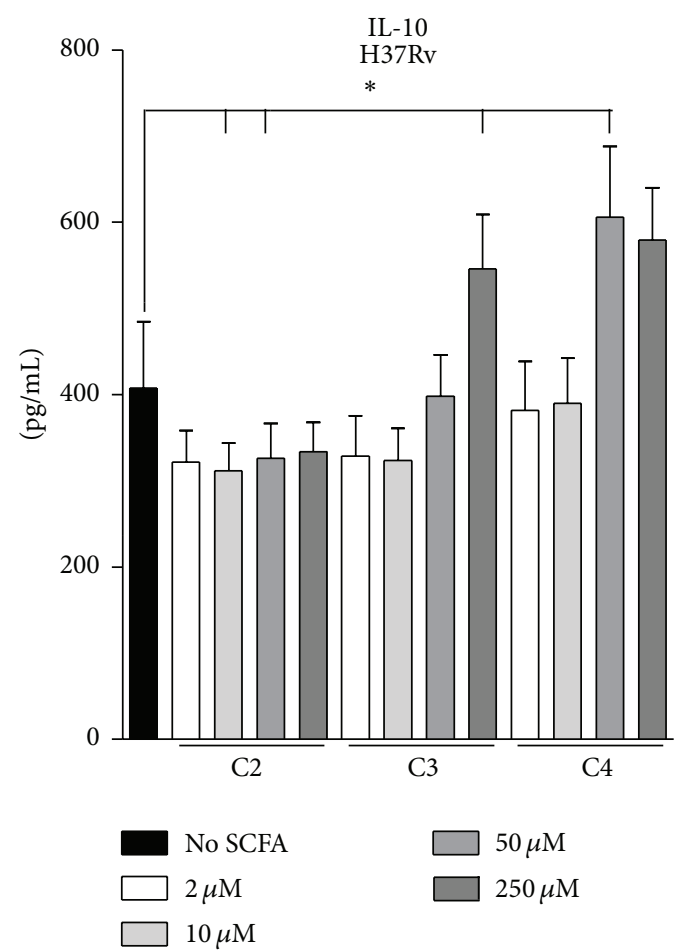

(a)

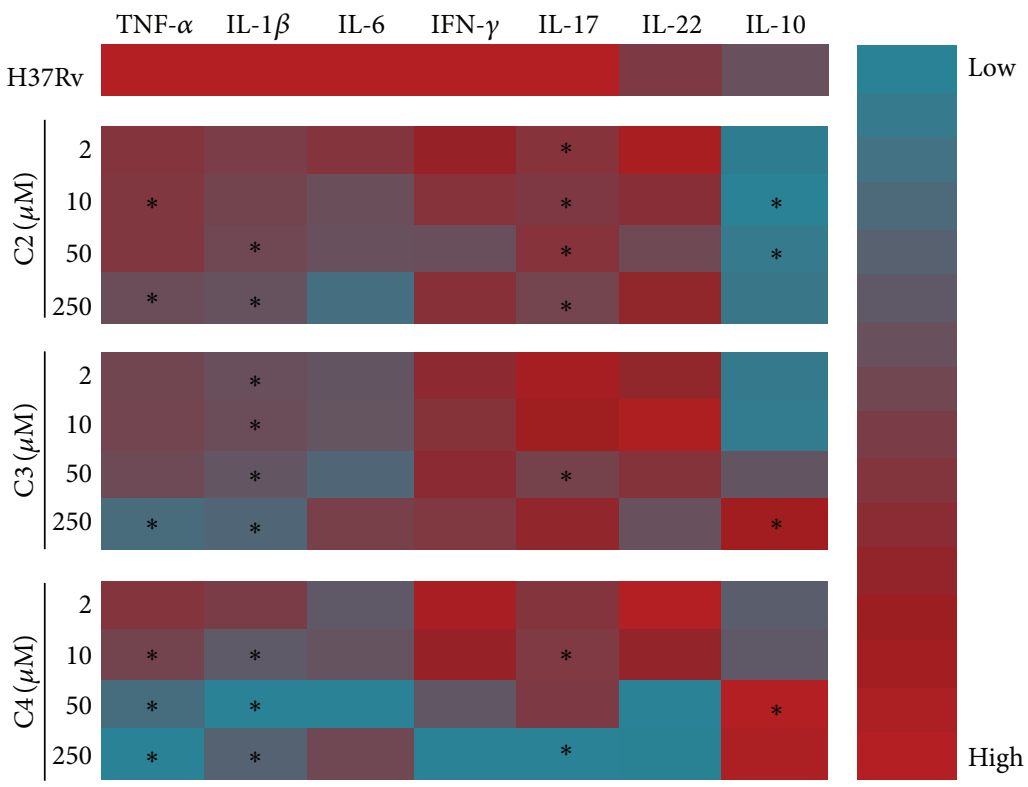

(b)

FIGURE 1: Short-chain fatty acids inhibit Mtb-induced cytokine responses. (a) PBMCs were preincubated with 2-250 $\mu$ M SCFAs for $1 \mathrm{~h}$ prior to stimulation with Mtb lysate for $24 \mathrm{~h}$ and $7 \mathrm{~d}$. Hereafter TNF- $\alpha$, IL-6, IL-10, IFN- $\gamma$, IL-17, and IL-22 were measured in supernatants by ELISA. Data are means \pm SEM $(n=6)$, using Wilcoxon signed-rank test, representative of 2 independent experiments. ${ }^{*} p<0.05$. (b) Heat map of log-transformed mean cytokine responses as measured by ELISA, showing cytokines upregulated (red) and downregulated (blue) upon H37Rv stimulation in the presence of different doses of SCFAs. Cytokine responses are shown as compared to H37Rv stimulation alone. ${ }^{*} p<0.05$.

blocking IL-10 specifically using an anti-IL-10 antibody could counteract the inhibitory effects of $\mathrm{C} 4$ on proinflammatory cytokine response. Blocking IL-10 completely restored IL-6 cytokine responses in response to $\mathrm{H} 37 \mathrm{Rv}$ and $\mathrm{C} 4$, while TNF$\alpha$ and IL- $1 \beta$ production was partly restored (Figure $5(\mathrm{c})$ ). This suggests an important role for intermediary protein synthesis, specifically IL-10, in mediating the anti-inflammatory effects of C4.

\section{Discussion}

$\mathrm{DM}$ is associated with a threefold increased risk of active $\mathrm{TB}$, but the underlying immunological mechanisms remain largely unknown $[3,12,13]$. Alterations in the gut microbiota of DM patients are associated with changes in plasma SCFA concentrations. Multiple papers have reported a decrease in C4-producing bacteria in type $2 \mathrm{DM}$ patients $[18,19,21$, $23,24]$. We here show that SCFAs, especially C4, exhibit anti-inflammatory properties; low doses of $\mathrm{C} 4$ decreased Mtb-induced proinflammatory cytokine responses on both the transcriptional level and the translational level, while production of IL-10 was increased. This anti-inflammatory effect was independent of HDAC activity, Toll-like receptor signalling, the eicosanoid pathway, or cellular metabolism.
We observed a general anti-inflammatory effect of C2, C3, and $\mathrm{C} 4$ on Mtb-induced cytokine production. C4 induced some of the most significant and most potent changes in cytokine responses, which is in line with published results [29], although our study is the first to examine the effects of physiological concentrations of SCFAs on Mtb-induced cytokine responses in vitro. Several observations were made regarding the effect of SCFA on cytokines. Firstly, the inhibitory effect of all three SCFAs on production of TNF$\alpha$ and IL-1 $\beta$ was comparable for Mtb and LPS stimulation. However, while C 3 and C4 had a clear effect on LPS-induced IL-6 release, this was not found for Mtb. This suggests that SCFAs do not affect Mtb-induced IL-6, although IL-6 has been assigned an important role in Mtb host responses [59-62]. Secondly, C2, C3, and C4 had a much stronger inhibitory effect on T-cell derived cytokine IL-17 than on T-cell derived cytokines IFN- $\gamma$ and IL-22. Because C4 also strongly decreased Th17 proliferation (Supplementary Figure 5 A), SCFAs may affect Th17 subsets more than other T-cell subsets. This may be of great relevance since Th17 cells, and IL-17 in particular, have been reported to be essential in protective immunity against Mtb $[63,64]$ but inversely associated with DM complications [65-67]. Lastly, the stimulatory effect of C3 and C4 on anti-inflammatory IL-10 release was Mtbspecific and was not seen with LPS stimulation. IL-10 has 

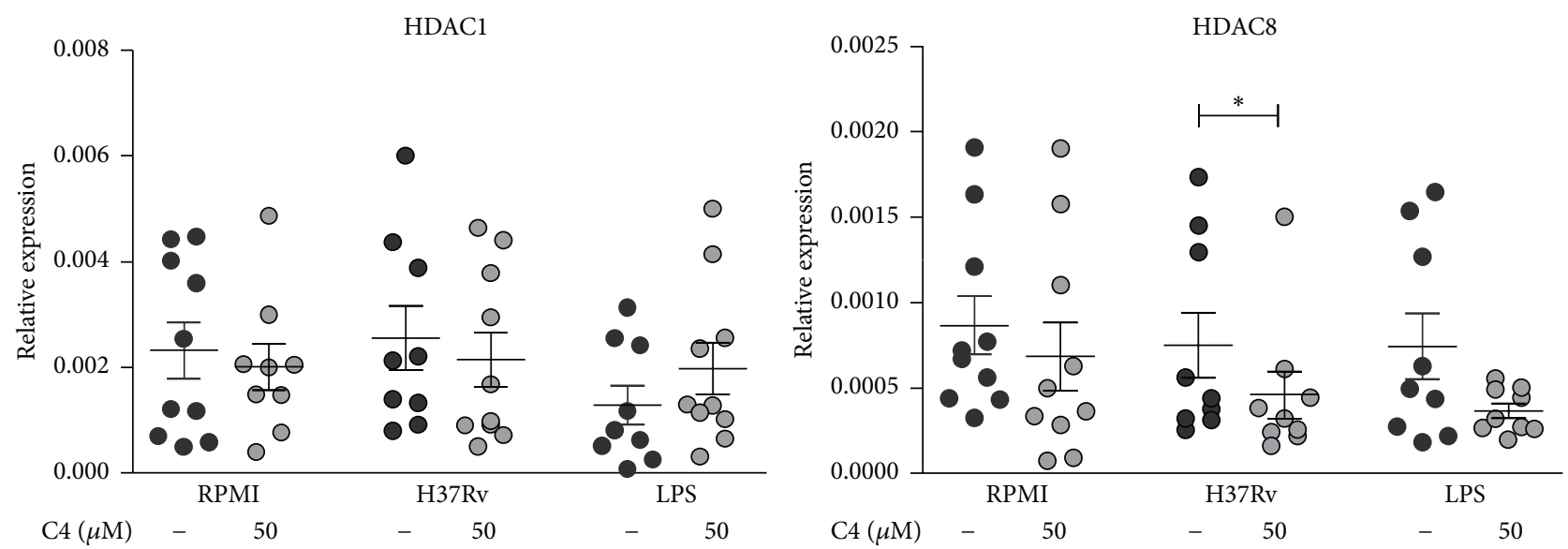

(a)

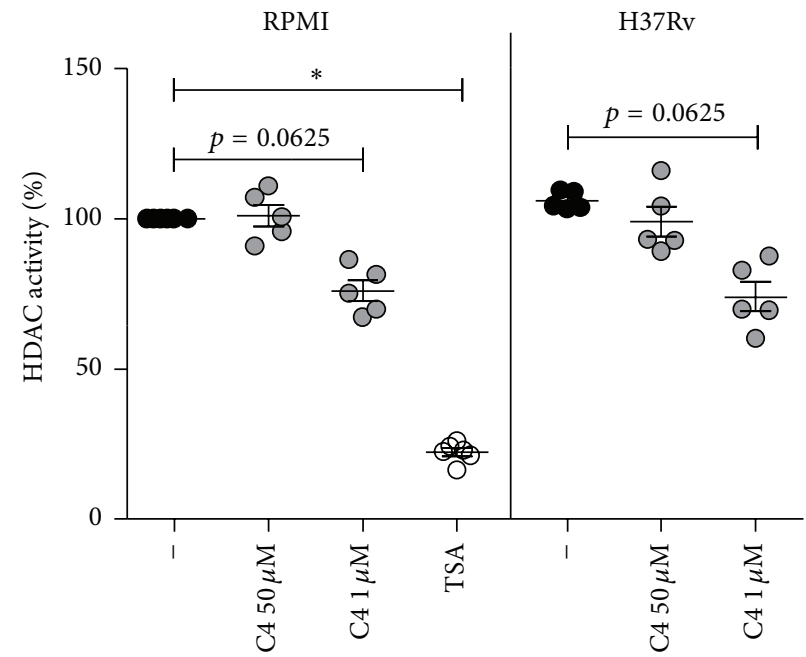

(b)

FIGURE 2: Influence of butyrate on HDAC expression and activity. (a) PBMCs were preincubated with $50 \mu \mathrm{M}$ C4 for $1 \mathrm{~h}$ prior to stimulation with Mtb lysate or LPS for $4 \mathrm{~h}$. Gene expression levels of HDACl and HDAC8 were measured by qPCR. Data are means \pm SEM $(n=10)$, using Wilcoxon signed-rank test, representative of 3 independent experiments. ${ }^{*} p<0.05$. (b) Percentage of general HDAC activity relative to RPMI stimulated PBMCs, as measured by levels of substrate deacetylation after $30 \mathrm{~min}$ of preincubation with C4 (50 $\mu \mathrm{M})$ and 30 min of stimulation with Mtb lysate. Data are means $\pm \operatorname{SEM}(n=5$ to 6$)$, using Wilcoxon signed-rank test, representative of 3 independent experiments. ${ }^{*} p<0.05$.

been delineated as an important mediator in Mtb infection: it has been reported to block bacterial killing in Mtb-infected macrophages, suppress multinucleated giant cell formation and cytokine production, and inhibit the development of protective immunity [68-74]. In contrast to TB, IL-10 may have a protective role in type $2 \mathrm{DM}$ by reducing insulin resistance and obesity [75-77]. Therefore, the increase in IL10 production we see as induced by $\mathrm{C} 4$ is very relevant for the course of both DM and TB disease.

We examined several possible mechanisms underlying the effect of $\mathrm{C} 4$ on cytokine production, starting with HDAC activity, which is known to be inhibited by SCFAs. C4 at a physiological low dose of $50 \mu \mathrm{M}$ had little effect, while millimolar concentrations of C4 (as used in other studies [36, 41-44]) decreased HDAC activity upon H37Rv stimulation. This is expected as $\mathrm{IC}_{50}$ values of HDAC inhibition by $\mathrm{C} 4$ are $>100 \mu \mathrm{M}$, depending on the class of HDAC [43].
The strongest effect was noted for HDAC8, which is reported to be most sensitive to $\mathrm{C} 4$ [43]. This argues that physiological C4 concentrations in human plasma do not exert HDAC inhibition and underlines the importance of using physiological concentrations within in vitro experimental models.

In contrast to a previous study [50], we observed a decreased gene expression of the TLR modulatory factors SOCS1 and Tollip when PBMCs were stimulated in the presence of $\mathrm{C} 4$, which thus cannot explain the inhibitory effects on cytokine production. This, together with our data showing that $\mathrm{C} 4$ does not affect MAP kinase activity, suggests that C4 does not act at the level of TLR signalling, as shown previously [36].

As a third possible mechanism, we assessed whether C4 exerts its effects through eicosanoid metabolism. The eicosanoid pathway is under influence of SCFAs $[30,56]$ and may modulate the host response to Mtb [51-55]. C4 did not 


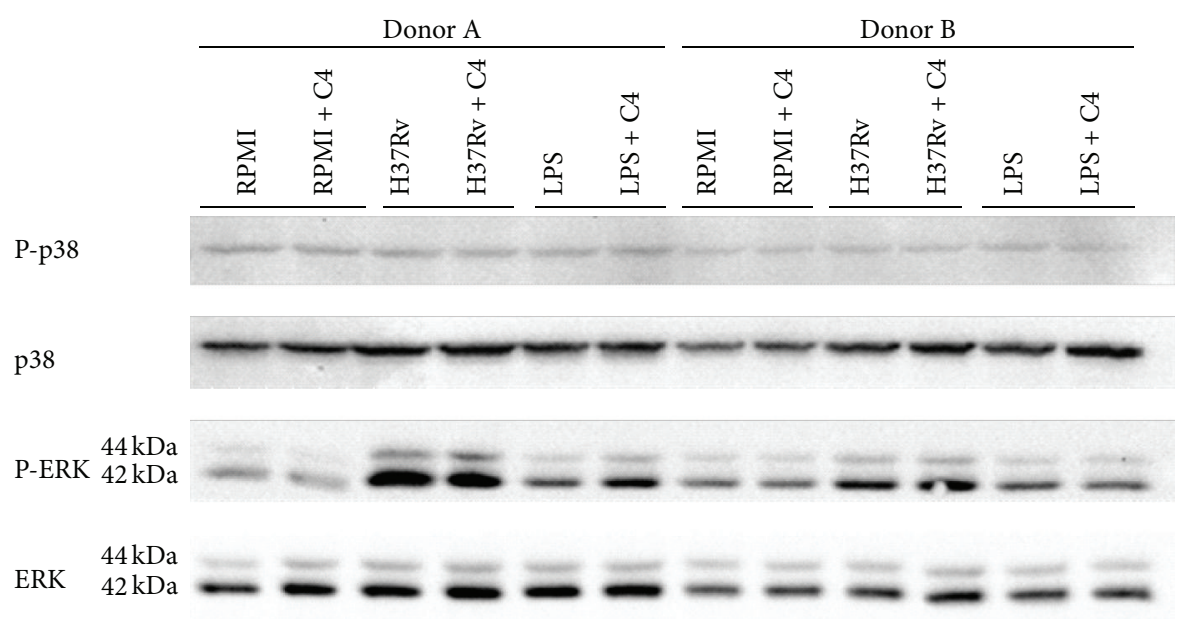

(a)
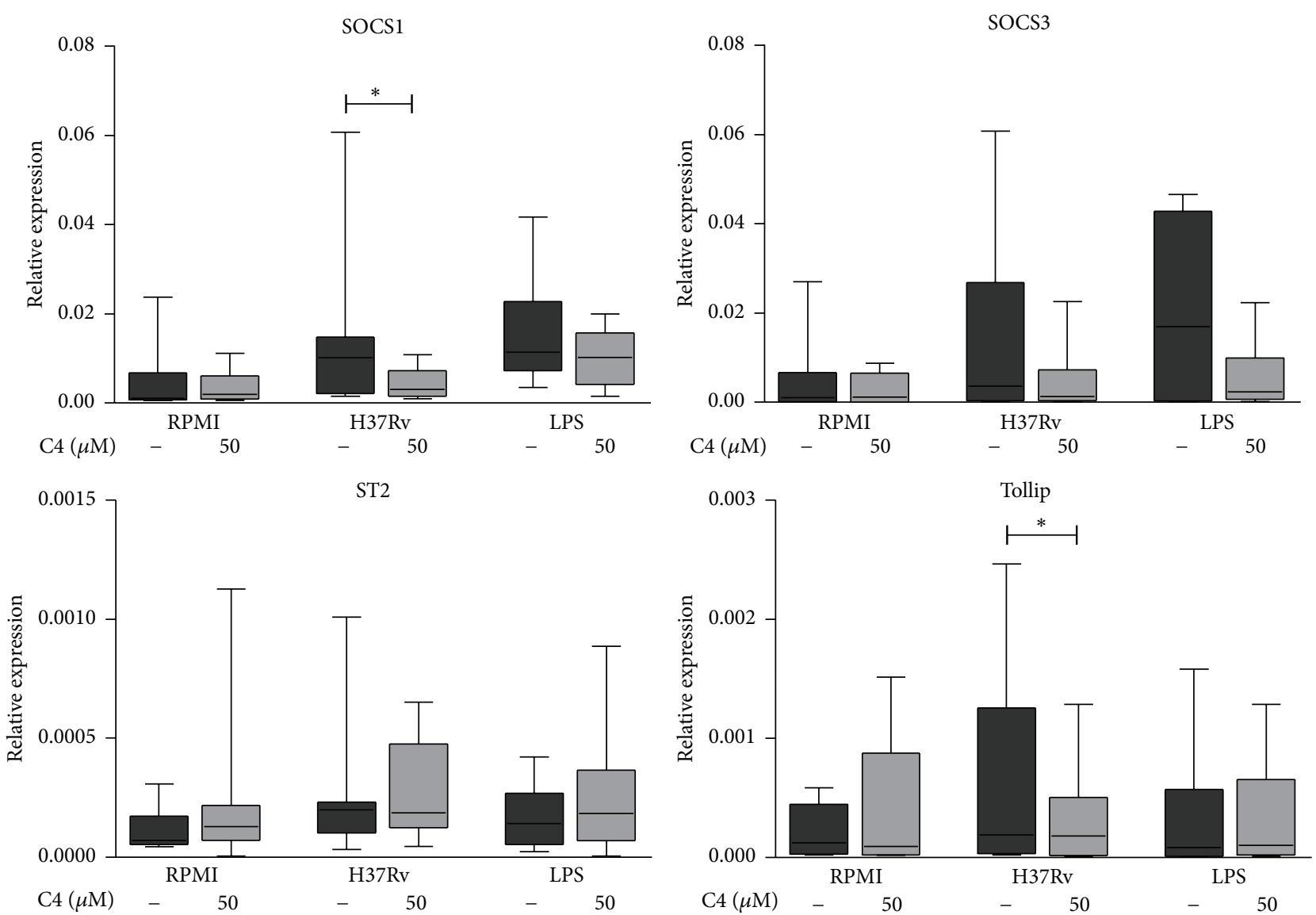

(b)

FIGURE 3: The effects of butyrate on TLR signalling mediators. (a) PBMCs were preincubated with $50 \mu \mathrm{M} \mathrm{C4}(1 \mathrm{~h})$ and stimulated with Mtb lysate or LPS. Cell lysates were harvested at $30 \mathrm{~min}$ after stimulation. Phospho-p38, p38, phospho-ERK, and ERK protein levels were determined by Western blot using specific antibodies $(n=2)$. (b) Gene expression levels of SOCS1, SOCS3, ST2, and Tollip in PBMCs preincubated with $50 \mu \mathrm{M} \mathrm{C} 4(1 \mathrm{~h})$ and stimulated with Mtb lysate or LPS ( $4 \mathrm{~h})$ as measured by qPCR. The box plot represents median with first and third quartiles; the whiskers represent minimum and maximum values. $n=10$, using Wilcoxon signed-rank test, representative of 3 independent experiments. ${ }^{*} p<0.05$. 


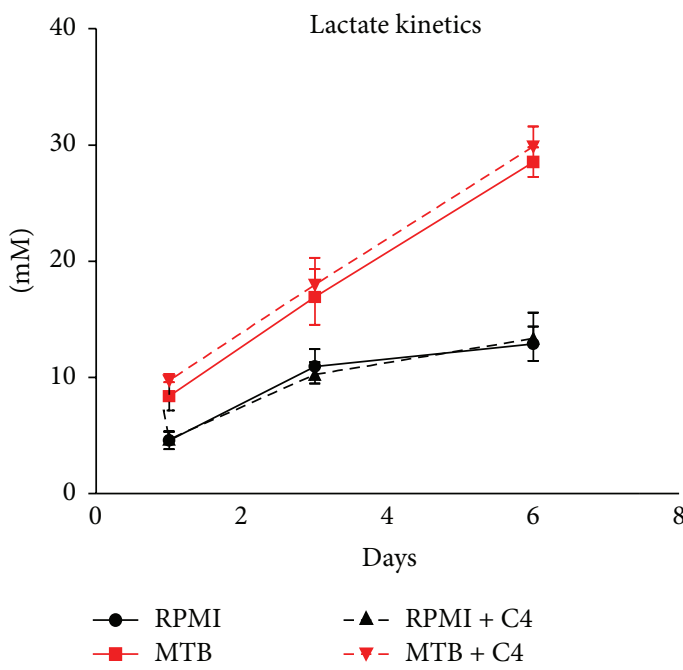

(a)
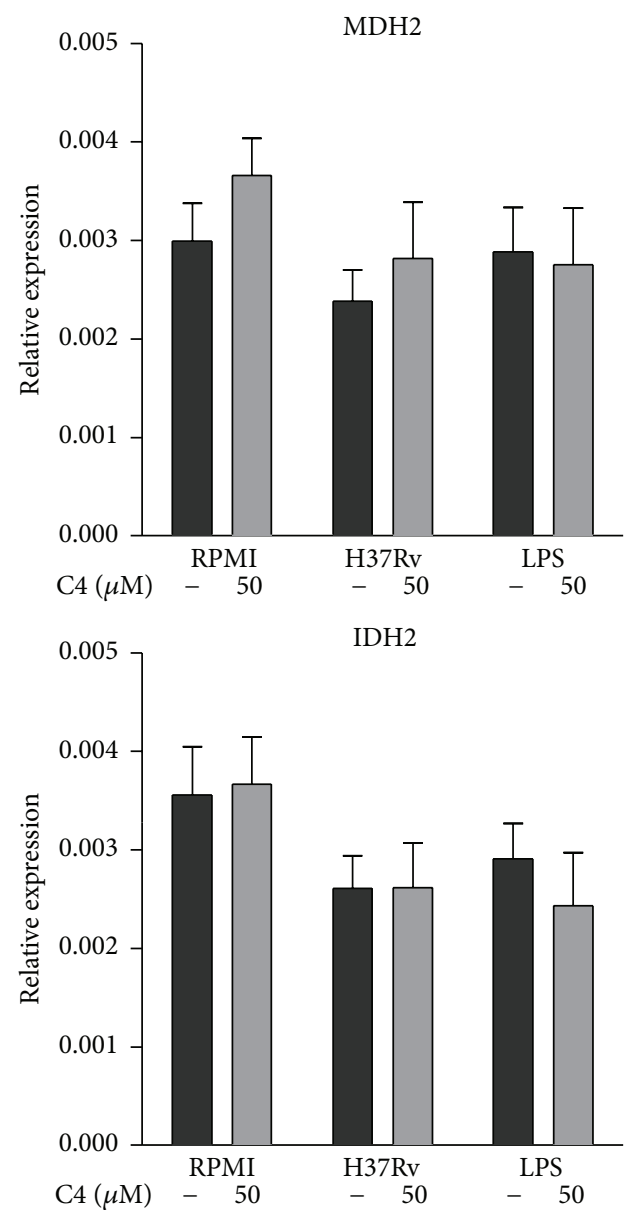

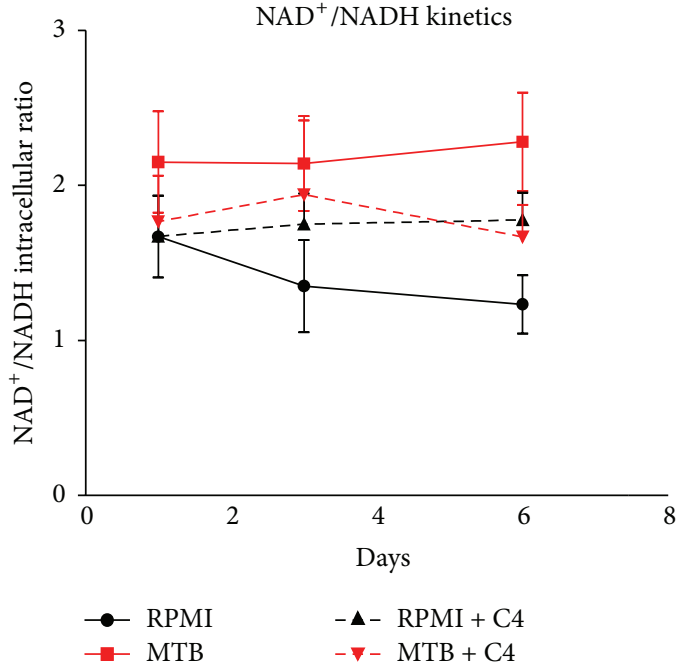

(b)
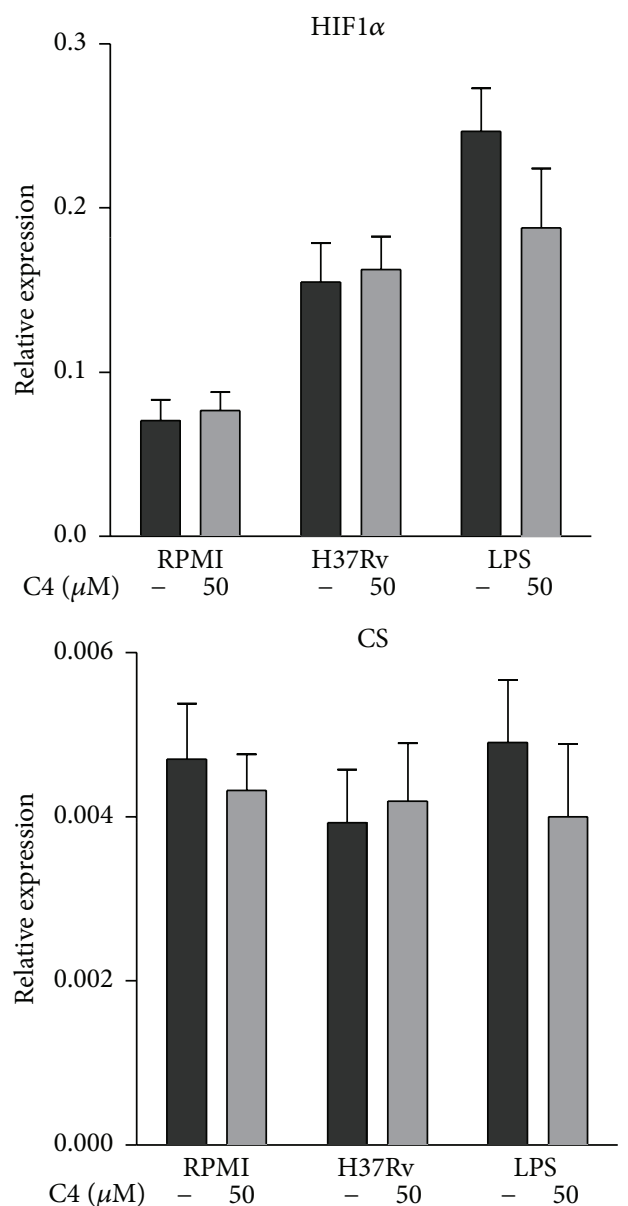

(c)

FIGURE 4: Influence of butyrate on cellular metabolism. ( $a$ and $b$ ) Kinetics of lactate production (a) and intracellular NAD $/ \mathrm{NADH}$ ratios (b) from days 1, 3, and 7 of PBMCs preincubated with $50 \mu \mathrm{M} \mathrm{C} 4(1 \mathrm{~h})$ with and without stimulation with Mtb lysate. Data are means \pm SEM ( $n=3$ to 5), using Wilcoxon signed-rank test, representative of 1-2 independent experiments. (c) Expression levels of glycolysis and TCA cycle genes in PBMCs preincubated with $50 \mu \mathrm{M} \mathrm{C} 4(1 \mathrm{~h})$ and stimulated with Mtb lysate or LPS $(4 \mathrm{~h})$ as measured by qPCR. Data are means \pm SEM $(n=6)$, using Wilcoxon signed-rank test, representative of 2 independent experiments. 

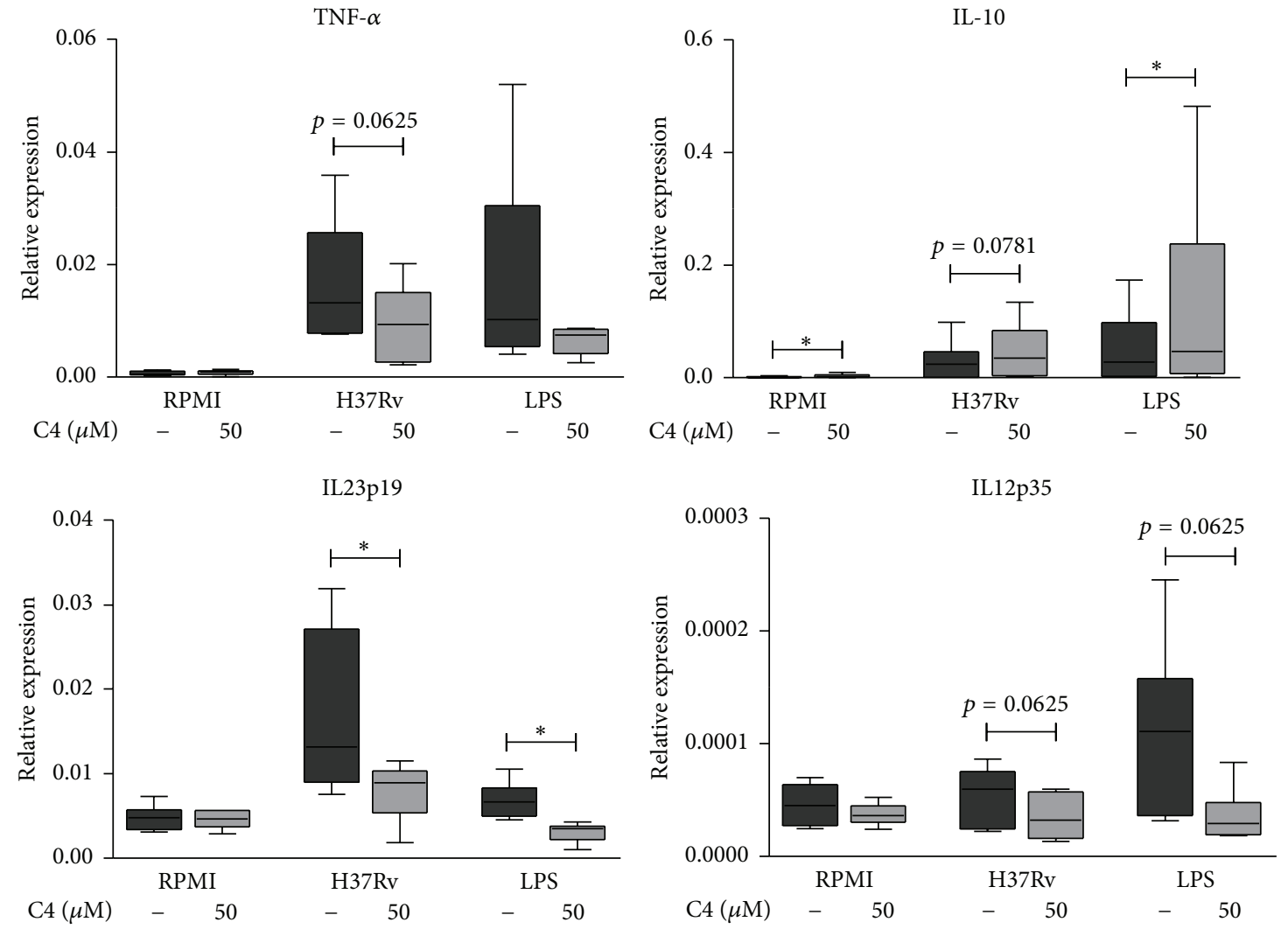

(a)

H37Rv
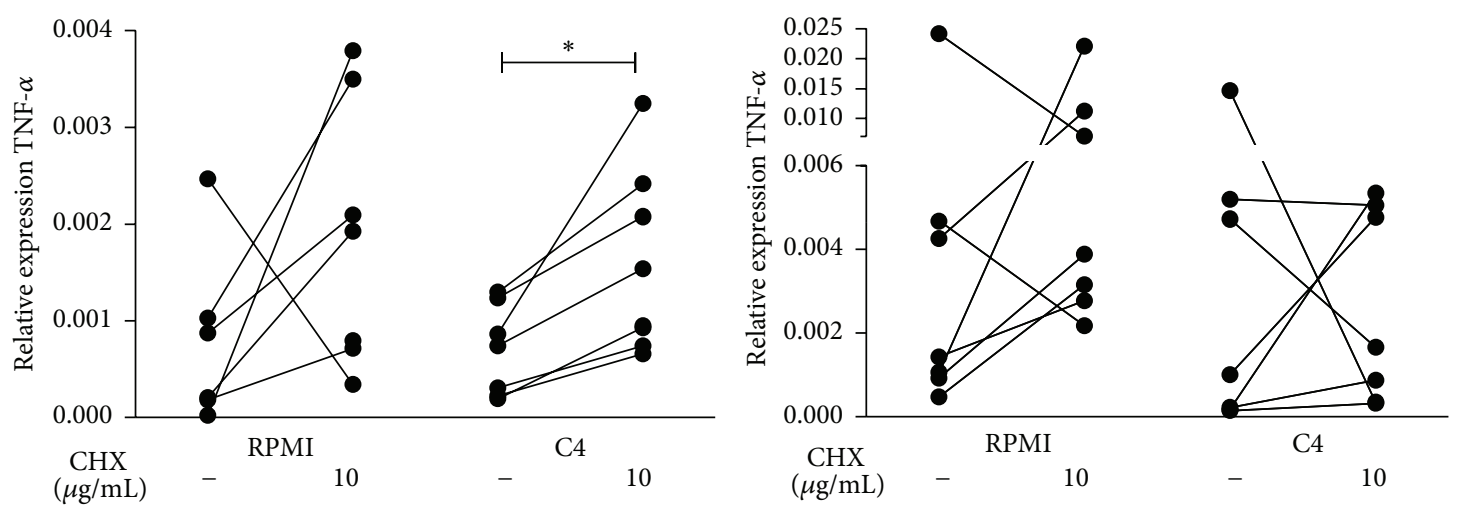

(b)
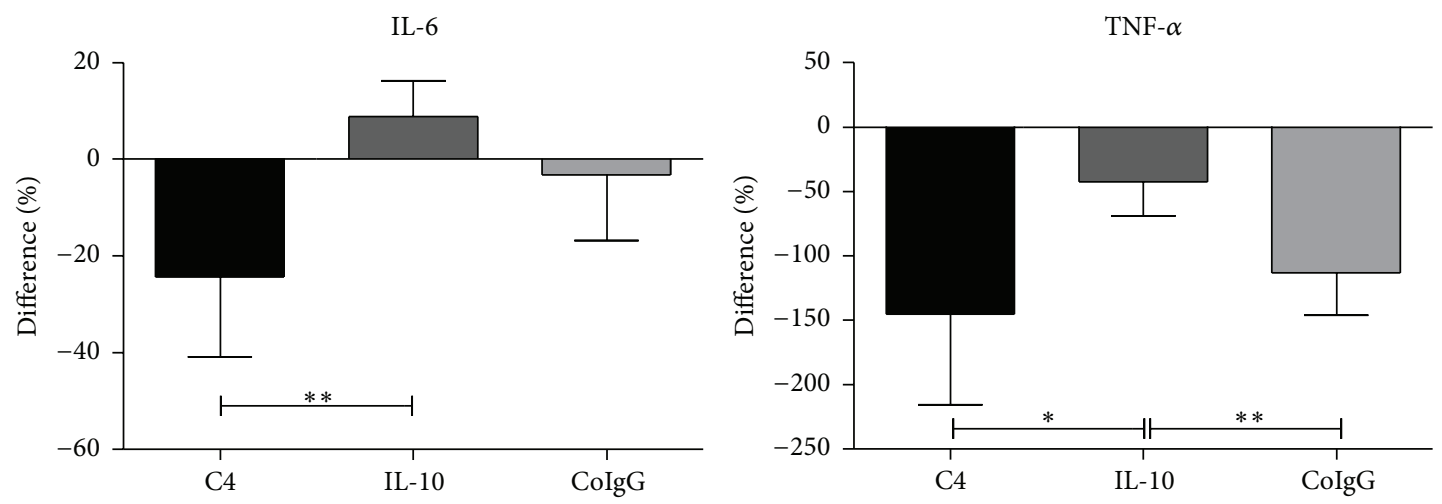

FIgUre 5: Continued. 


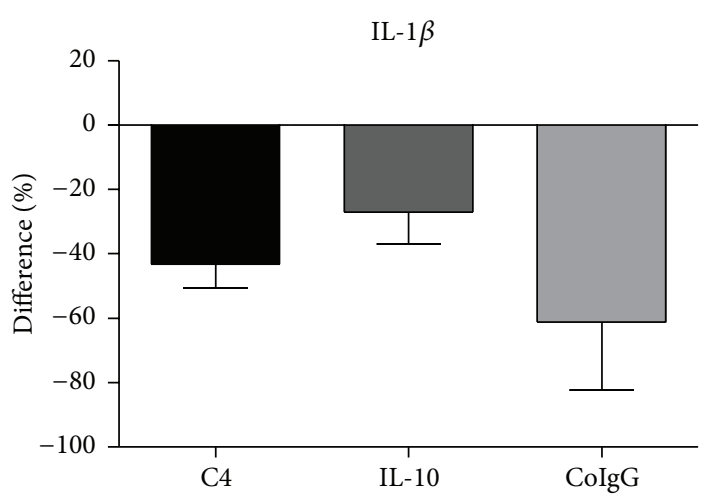

(c)

FIGURE 5: Butyrate transcriptionally influences cytokine responses to Mtb, possibly mediated through IL-10. (a) Cytokine gene expression levels in PBMCs preincubated with $50 \mu \mathrm{M} \mathrm{C} 4$ for $1 \mathrm{~h}$ prior to stimulation with Mtb lysate or LPS for $4 \mathrm{~h}$, as measured by qPCR. The box plot represents median with first and third quartiles; the whiskers represent minimum and maximum values. $n=6$ to 10 , using Wilcoxon signedrank test, representative of $2+$ independent experiments. ${ }^{*} p<0.05$. (b) To block translation, PBMCs were preincubated with cycloheximide (CHX) for $1 \mathrm{~h}$ prior to $1 \mathrm{~h}$ incubation with $\mathrm{C} 4(50 \mu \mathrm{M})$. TNF- $\alpha$ transcript levels were measured by qPCR $4 \mathrm{~h}$ after stimulation with Mtb lysate or LPS. Data are single values $(n=6$ to 7$)$, using Wilcoxon signed-rank test, representative of 3 independent experiments. ${ }^{*} p<0.05$. (c) To block IL-10 activity, PBMCs were preincubated with IL-10 and C4 (50 $\mu \mathrm{M})$ for $1 \mathrm{~h}$. IL-6, TNF- $\alpha$, and IL- $1 \beta$ production was measured by ELISA after $24 \mathrm{~h}$ of stimulation with Mtb lysate. Data are means \pm SEM ( $n=10$ to 12$)$, using Wilcoxon signed-rank test, representative of 4 independent experiments.

affect expression of COX-2, a key enzyme in the eicosanoid pathway, in contrast to previous reports that used supraphysiological C4 concentrations [30,56]. In addition, inhibition of the eicosanoid pathway using aspirin did not counteract the effects of C4. Therefore, the eicosanoid pathway is unlikely to be involved in mediating the effects of $\mathrm{C} 4$.

The effect of diabetes on the host immune response to Mtb might also be explained by altered cellular metabolism, with a possible role for SCFA. Cellular metabolism is increasingly linked to immunology [78-80]. One previous study noted that $\mathrm{C} 4$ influences metabolic processes in colonocytes [58], which use butyrate as their primary energy source [58]. However, we did not observe any effect of C4 on lactate production, the redox status, TCA cycle gene expression, or $\beta$-oxidation in PBMCs. We therefore conclude that cellular metabolism does not mediate the effect of $\mathrm{C} 4$ on $\mathrm{Mtb}$ induced cytokine production.

Finally, we further examined the effect of $\mathrm{C} 4$ on the anti-inflammatory cytokine IL-10. IL-10 is detrimental to TB outcome, while it may improve DM symptoms [6877]. In line with previous studies [33, 81, 82], we report an upregulation in IL-10 production induced by C4. Removal of all intermediary protein, including IL-10, from PBMCs stimulated with $\mathrm{H} 37 \mathrm{Rv}$ and $\mathrm{C} 4$ led to a significant increase in TNF- $\alpha$ transcript, thereby counteracting the decrease in TNF- $\alpha$ production induced by $\mathrm{C} 4$. Moreover, blocking IL-10 specifically fully restored IL-6 responses in PBMCs stimulated with $\mathrm{H} 37 \mathrm{Rv}$ and $\mathrm{C} 4$ and partly restored TNF$\alpha$ and IL- $1 \beta$ responses. These data suggest that the antiinflammatory cytokine IL-10 may play a role in the inhibitory effects of C4 on Mtb-induced inflammatory responses.

Currently, much research focuses on modulation of the gut microbiota in order to treat obesity and type 2 DM [8386]. Administration of sodium butyrate or butyrate-inducing probiotics in mice significantly increased plasma insulin levels and insulin sensitivity and suppressed body weight gain [87-89]. The anti-inflammatory effects of C4 may attenuate the chronic inflammatory state associated with type $2 \mathrm{DM}$, thereby improving DM symptoms. If chronic inflammation is a causal factor of the impaired host response to Mtb in type 2 DM patients, attenuation of this hyperinflammatory state may improve not only DM but also TB outcome in patients with coincident $\mathrm{DM}$ and TB disease.

Some limitations of our study need to be addressed. Firstly, we studied the effects of C4 on Mtb-induced inflammation in PBMCs in vitro. SCFA levels have been shown to be altered in DM patients [18-22], but this in vitro model does not include other aspects of the pathophysiology of DM such as hyperglycemia, hyperinsulinemia, or dyslipidemia, phenomena which have also been reported to affect immunity [90-94]. Furthermore, DM medications possibly interfere with the intestinal microbiota and immune responses in patients [95-97]. It is therefore unclear how accurately our in vitro model reflects the in vivo situation in DM patients.

In conclusion, we show an anti-inflammatory effect of low, physiological doses of C4 on Mtb-induced inflammatory responses. The anti-inflammatory cytokine IL-10 may play a role in mediating the inhibitory effects of $\mathrm{C} 4$ on the host immune response to $\mathrm{Mtb}$. Further studies are needed to precisely explore the pathways by which physiological concentrations of $\mathrm{C} 4$ exert their anti-inflammatory effects and to define the mechanism of increased TB sensitivity in type 2 DM patients. Moreover, current research on modulating gut microbiota in DM should include its possible effects on TB.

\section{Conflict of Interests}

The authors declare that there is no conflict of interests regarding the publication of this paper. 


\section{Acknowledgment}

This study was supported by the TANDEM (Tuberculosis and Diabetes Mellitus) Grant of the ECFP7 (European Union's Seventh Framework Programme) under Grant Agreement no. 305279 .

\section{References}

[1] WHO, Global Tuberculosis Report 2014, World Health Organization, Geneva, Switzerland, 2014, http://apps.who.int/iris/ bitstream/10665/137094/1/9789241564809_eng.pdf?ua=1.

[2] IDF, IDF Diabetes Atlas Update Poster, IDF, 6th edition, 2014, http://www.idf.org/sites/default/files/EN_6E_Atlas_Full_0.pdf.

[3] C. Y. Jeon and M. B. Murray, "Diabetes mellitus increases the risk of active tuberculosis: a systematic review of 13 observational studies," PLoS Medicine, vol. 5, no. 7, article e152, 2008.

[4] R. Ruslami, R. E. Aarnoutse, B. Alisjahbana, A. J. A. M. Van Der Ven, and R. Van Crevel, "Implications of the global increase of diabetes for tuberculosis control and patient care," Tropical Medicine and International Health, vol. 15, no. 11, pp. 1289-1299, 2010.

[5] B. Dixon, "Diabetes and tuberculosis: an unhealthy partnership," The Lancet Infectious Diseases, vol. 7, no. 7, p. 444, 2007.

[6] B. I. Restrepo and L. S. Schlesinger, "Impact of diabetes on the natural history of tuberculosis," Diabetes Research and Clinical Practice, vol. 106, no. 2, pp. 191-199, 2014.

[7] C. R. Stevenson, N. G. Forouhi, G. Roglic et al., "Diabetes and tuberculosis: the impact of the diabetes epidemic on tuberculosis incidence," BMC Public Health, vol. 7, article 234, 2007.

[8] M. A. Baker, H.-H. Lin, H.-Y. Chang, and M. B. Murray, "The risk of tuberculosis disease among persons with diabetes mellitus: a prospective cohort study," Clinical Infectious Diseases, vol. 54, no. 6, pp. 818-825, 2012.

[9] C. Y. Jeon, M. B. Murray, and M. A. Baker, "Managing tuberculosis in patients with diabetes mellitus: why we care and what we know," Expert Review of Anti-Infective Therapy, vol. 10, no. 8, pp. 863-868, 2012.

[10] M. E. Jimenez-Corona, L. P. Cruz-Hervert, L. García-García et al., "Association of diabetes and tuberculosis: impact on treatment and post-treatment outcomes," Thorax, vol. 68, no. 3, pp. 214-220, 2013.

[11] B. Alisjahbana, E. Sahiratmadja, E. J. Nelwan et al., "The effect of type 2 diabetes mellitus on the presentation and treatment response of pulmonary tuberculosis," Clinical Infectious Diseases, vol. 45, no. 4, pp. 428-435, 2007.

[12] A. L. Riza, F. Pearson, C. Ugarte-Gil et al., "Clinical management of concurrent diabetes and tuberculosis and the implications for patient services," The Lancet Diabetes and Endocrinology, vol. 2, no. 9, pp. 740-753, 2014.

[13] K. Ronacher, S. A. Joosten, R. van Crevel, H. M. Dockrell, G. Walzl, and T. H. M. Ottenhoff, "Acquired immunodeficiencies and tuberculosis: focus on HIV/AIDS and diabetes mellitus," Immunological Reviews, vol. 264, no. 1, pp. 121-137, 2015.

[14] N. P. Kumar, V. V. Banurekha, D. Nair et al., "Coincident prediabetes is associated with dysregulated cytokine responses in pulmonary tuberculosis," PLoS ONE, vol. 9, no. 11, Article ID e112108, 2014.

[15] N. P. Kumar, P. J. George, P. Kumaran, C. K. Dolla, T. B. Nutman, and S. Babu, "Diminished systemic and antigen-specific type 1 , type 17 , and other proinflammatory cytokines in diabetic and prediabetic individuals with latent mycobacterium tuberculosis infection," The Journal of Infectious Diseases, vol. 210, no. 10, pp. 1670-1678, 2014.

[16] N. P. Kumar, R. Sridhar, V. V. Banurekha, M. S. Jawahar, T. B. Nutman, and S. Babu, "Expansion of pathogen-specific Thelper 1 and T-helper 17 cells in pulmonary tuberculosis with coincident type 2 diabetes mellitus," Journal of Infectious Diseases, vol. 208, no. 5, pp. 739-748, 2013.

[17] B. I. Restrepo, S. P. Fisher-Hoch, P. A. Pino et al., "Tuberculosis in poorly controlled type 2 diabetes: altered cytokine expression in peripheral white blood cells," Clinical Infectious Diseases, vol. 47, no. 5, pp. 634-641, 2008.

[18] J.-P. Furet, L.-C. Kong, J. Tap et al., "Differential adaptation of human gut microbiota to bariatric surgery-induced weight loss: links with metabolic and low-grade inflammation markers," Diabetes, vol. 59, no. 12, pp. 3049-3057, 2010.

[19] F. H. Karlsson, V. Tremaroli, I. Nookaew et al., "Gut metagenome in European women with normal, impaired and diabetic glucose control," Nature, vol. 498, no. 7452, pp. 99-103, 2013.

[20] N. Larsen, F. K. Vogensen, F. W. J. van den Berg et al., "Gut microbiota in human adults with type 2 diabetes differs from non-diabetic adults," PLoS ONE, vol. 5, no. 2, Article ID e9085, 2010.

[21] J. Qin, J. Wang, Y. Li et al., "A metagenome-wide association study of gut microbiota in type 2 diabetes," Nature, vol. 490, no. 7418, pp. 55-60, 2012.

[22] K. M. Maslowski, A. T. Vieira, A. Ng et al., "Regulation of inflammatory responses by gut microbiota and chemoattractant receptor GPR43," Nature, vol. 461, no. 7268, pp. 1282-1286, 2009.

[23] M. Remely, E. Aumueller, C. Merold et al., "Effects of short chain fatty acid producing bacteria on epigenetic regulation of FFAR3 in type 2 diabetes and obesity," Gene, vol. 537, no. 1, pp. 85-92, 2014.

[24] X. Zhang, D. Shen, Z. Fang et al., "Human gut microbiota changes reveal the progression of glucose intolerance," PLoS ONE, vol. 8, no. 8, Article ID e71108, 2013.

[25] U. Böcker, T. Nebe, F. Herweck et al., "Butyrate modulates intestinal epithelial cell-mediated neutrophil migration," Clinical and Experimental Immunology, vol. 131, no. 1, pp. 53-60, 2003.

[26] M. A. Cox, J. Jackson, M. Stanton et al., "Short-chain fatty acids act as antiinflammatory mediators by regulating prostaglandin $\mathrm{E}_{2}$ and cytokines," World Journal of Gastroenterology, vol. 15, no. 44, pp. 5549-5557, 2009.

[27] L. Klampfer, J. Huang, T. Sasazuki, S. Shirasawa, and L. Augenlicht, "Inhibition of interferon gamma signaling by the short chain fatty acid butyrate," Molecular Cancer Research, vol. 1, no. 11, pp. 855-862, 2003.

[28] M.-C. Maa, M. Y. Chang, M.-Y. Hsieh et al., "Butyrate reduced lipopolysaccharide-mediated macrophage migration by suppression of Src enhancement and focal adhesion kinase activity," Journal of Nutritional Biochemistry, vol. 21, no. 12, pp. 1186-1192, 2010.

[29] K. Meijer, P. de Vos, and M. G. Priebe, "Butyrate and other shortchain fatty acids as modulators of immunity: what relevance for health?" Current Opinion in Clinical Nutrition and Metabolic Care, vol. 13, no. 6, pp. 715-721, 2010.

[30] J. J. Kovarik, M. A. Hölzl, J. Hofer et al., "Eicosanoid modulation by the short-chain fatty acid n-butyrate in human monocytes," Immunology, vol. 139, no. 3, pp. 395-405, 2013. 
[31] S. Tedelind, F. Westberg, M. Kjerrulf, and A. Vidal, "Antiinflammatory properties of the short-chain fatty acids acetate and propionate: a study with relevance to inflammatory bowel disease," World Journal of Gastroenterology, vol. 13, no. 20, pp. 2826-2832, 2007.

[32] M. A. R. Vinolo, H. G. Rodrigues, R. T. Nachbar, and R. Curi, "Regulation of inflammation by short chain fatty acids," Nutrients, vol. 3, no. 10, pp. 858-876, 2011.

[33] E. Bailón, M. Cueto-Sola, P. Utrilla et al., "Butyrate in vitro immune-modulatory effects might be mediated through a proliferation-related induction of apoptosis," Immunobiology, vol. 215, no. 11, pp. 863-873, 2010.

[34] T. Kurita-Ochiai, K. Ochiai, and K. Fukushima, "Butyric acidinduced T-cell apoptosis is mediated by caspase- 8 and -9 activation in a Fas-independent manner," Clinical and Diagnostic Laboratory Immunology, vol. 8, no. 2, pp. 325-332, 2001.

[35] M. Aoyama, J. Kotani, and M. Usami, "Butyrate and propionate induced activated or non-activated neutrophil apoptosis via HDAC inhibitor activity but without activating GPR-41/GPR43 pathways," Nutrition, vol. 26, no. 6, pp. 653-661, 2010.

[36] P. V. Chang, L. Hao, S. Offermanns, and R. Medzhitov, “The microbial metabolite butyrate regulates intestinal macrophage function via histone deacetylase inhibition," Proceedings of the National Academy of Sciences of the United States of America, vol. 111, no. 6, pp. 2247-2252, 2014.

[37] J.-S. Park, E.-J. Lee, J.-C. Lee, W.-K. Kim, and H.-S. Kim, "Antiinflammatory effects of short chain fatty acids in IFN-gammastimulated RAW 264.7 murine macrophage cells: involvement of NF-kappaB and ERK signaling pathways," International Immunopharmacology, vol. 7, no. 1, pp. 70-77, 2007.

[38] S. M. Behar, C. J. Martin, M. G. Booty et al., "Apoptosis is an innate defense function of macrophages against Mycobacterium tuberculosis," Mucosal Immunology, vol. 4, no. 3, pp. 279-287, 2011.

[39] J. H. Cummings, E. W. Pomare, H. W. J. Branch, C. P. E. Naylor, and G. T. MacFarlane, "Short chain fatty acids in human large intestine, portal, hepatic and venous blood," Gut, vol. 28, no. 10, pp. 1221-1227, 1987.

[40] C.-T. Zhu and D. M. Rand, "A hydrazine coupled cycling assay validates the decrease in redox ratio under starvation in Drosophila," PLoS ONE, vol. 7, no. 10, Article ID e47584, 2012.

[41] E. P. M. Candido, R. Reeves, and J. R. Davie, "Sodium butyrate inhibits histone deacetylation in cultured cells," Cell, vol. 14, no. 1, pp. 105-113, 1978.

[42] J. R. Davie, "Inhibition of histone deacetylase activity by butyrate," Journal of Nutrition, vol. 133, no. 7, supplement, pp. 2485S-2493S, 2003.

[43] M. C. P. Cleophas, T. O. Crisan, H. Lemmers et al., "Suppression of monosodium urate crystal-induced cytokine production by butyrate is mediated by the inhibition of class I histone deacetylases," Annals of the Rheumatic Diseases, 2015.

[44] M. Kilgore, C. A. Miller, D. M. Fass et al., "Inhibitors of class 1 histone deacetylases reverse contextual memory deficits in a mouse model of Alzheimer's disease," Neuropsychopharmacology, vol. 35, no. 4, pp. 870-880, 2010.

[45] J. Kleinnijenhuis, M. Oosting, L. A. B. Joosten, M. G. Netea, and R. Van Crevel, "Innate immune recognition of Mycobacterium tuberculosis," Clinical and Developmental Immunology, vol. 2011, Article ID 405310, 12 pages, 2011.

[46] T. K. Means, S. Wang, E. Lien, A. Yoshimura, D. T. Golenbock, and M. J. Fenton, "Human Toll-like receptors mediate cellular activation by Mycobacterium tuberculosis," Journal of Immunology, vol. 163, no. 7, pp. 3920-3927, 1999.

[47] Y. Bulut, K. S. Michelsen, L. Hayrapetian et al., "Mycobacterium tuberculosis heat shock proteins use diverse Toll-like receptor pathways to activate pro-inflammatory signals," The Journal of Biological Chemistry, vol. 280, no. 22, pp. 20961-20967, 2005.

[48] L. A. J. O’Neill, D. Golenbock, and A. G. Bowie, “The history of Toll-like receptors-redefining innate immunity," Nature Reviews Immunology, vol. 13, no. 6, pp. 453-460, 2013.

[49] M. Y. Peroval, A. C. Boyd, J. R. Young, and A. L. Smith, "A critical role for MAPK signalling pathways in the transcriptional regulation of toll like receptors," PLoS ONE, vol. 8, no. 2, Article ID e51243, 2013.

[50] S.-M. Gao, C.-Q. Chen, L.-Y. Wang et al., "Histone deacetylases inhibitor sodium butyrate inhibits JAK2/STAT signaling through upregulation of SOCS1 and SOCS3 mediated by HDAC8 inhibition in myeloproliferative neoplasms," Experimental Hematology, vol. 41, no. 3, pp. 261.e4-270.e4, 2013.

[51] S. M. Behar, M. Divangahi, and H. G. Remold, "Evasion of innate immunity by Mycobacterium tuberculosis: is death an exit strategy?" Nature Reviews Microbiology, vol. 8, no. 9, pp. 668674, 2010.

[52] M. Chen, M. Divangahi, H. Gan et al., "Lipid mediators in innate immunity against tuberculosis: opposing roles of $\mathrm{PGE}_{2}$ and $\mathrm{LXA}_{4}$ in the induction of macrophage death," Journal of Experimental Medicine, vol. 205, no. 12, pp. 2791-2801, 2008.

[53] M. Divangahi, M. Chen, H. Gan et al., "Mycobacterium tuberculosis evades macrophage defenses by inhibiting plasma membrane repair," Nature Immunology, vol. 10, no. 8, pp. 899906, 2009.

[54] J. R. Moreno, I. E. García, M. D. L. L. G. Hernández, D. A. Leon, R. Marquez, and R. H. Pando, "The role of prostaglandin $\mathrm{E}_{2}$ in the immunopathogenesis of experimental pulmonary tuberculosis," Immunology, vol. 106, no. 2, pp. 257-266, 2002.

[55] F. G. M. Snijdewint, P. Kaliński, E. A. Wierenga, J. D. Bos, and M. L. Kapsenberg, "Prostaglandin E2 differentially modulates cytokine secretion profiles of human Thelper lymphocytes," The Journal of Immunology, vol. 150, no. 12, pp. 5321-5329, 1993.

[56] X. Tong, L. Yin, and C. Giardina, "Butyrate suppresses Cox2 activation in colon cancer cells through HDAC inhibition," Biochemical and Biophysical Research Communications, vol. 317, no. 2, pp. 463-471, 2004.

[57] M. Usami, K. Kishimoto, A. Ohata et al., "Butyrate and trichostatin A attenuate nuclear factor kappaB activation and tumor necrosis factor alpha secretion and increase prostaglandin E2 secretion in human peripheral blood mononuclear cells," Nutrition Research, vol. 28, no. 5, pp. 321-328, 2008.

[58] D. R. Donohoe, N. Garge, X. Zhang et al., "The microbiome and butyrate regulate energy metabolism and autophagy in the mammalian colon," Cell Metabolism, vol. 13, no. 5, pp. 517-526, 2011.

[59] R. K. Dutta, M. Kathania, M. Raje, and S. Majumdar, "IL6 inhibits IFN-gamma induced autophagy in Mycobacterium tuberculosis H37Rv infected macrophages," International Journal of Biochemistry and Cell Biology, vol. 44, no. 6, pp. 942-954, 2012.

[60] C. H. Ladel, C. Blum, A. Dreher, K. Reifenberg, M. Kopf, and S. H. E. Kaufmann, "Lethal tuberculosis in interleukin-6-deficient mutant mice," Infection and Immunity, vol. 65, no. 11, pp. 48434849, 1997.

[61] A. N. Martinez, S. Mehra, and D. Kaushal, "Role of interleukin 6 in innate immunity to Mycobacterium tuberculosis infection," 
The Journal of Infectious Diseases, vol. 207, no. 8, pp. 1253-1261, 2013.

[62] V. Nagabhushanam, A. Solache, L.-M. Ting, C. J. Escaron, J. Y. Zhang, and J. D. Ernst, "Innate inhibition of adaptive immunity: Mycobacterium tuberculosis-induced IL-6 inhibits macrophage responses to IFN-gamma, Journal of Immunology, vol. 171, no. 9, pp. 4750-4757, 2003.

[63] R. Gopal, L. Monin, S. Slight et al., "Unexpected role for IL-17 in protective immunity against hypervirulent Mycobacterium tuberculosis HN878 infection," PLoS Pathogens, vol. 10, no. 5, Article ID e1004099, 2014.

[64] S. A. Khader, G. K. Bell, J. E. Pearl et al., "IL-23 and IL17 in the establishment of protective pulmonary CD4+ T cell responses after vaccination and during Mycobacterium tuberculosis challenge," Nature Immunology, vol. 8, no. 4, pp. 369-377, 2007.

[65] N. Afzal, S. Zaman, F. Shahzad, K. Javaid, A. Zafar, and A. H. Nagi, "Immune mechanisms in type-2 diabetic retinopathy," Journal of Pakistan Medical Association, vol. 65, no. 2, pp. 159163, 2015.

[66] N. Afzal, K. Javaid, W. Sami et al., "Inverse relationship of serum IL-17 with type-II diabetes retinopathy," Clinical Laboratory, vol. 59, no. 11-12, pp. 1311-1317, 2013.

[67] N. Afzal, S. Zaman, A. Asghar et al., "Negative association of serum IL-6 and IL-17 with type-II diabetes retinopathy," Iranian Journal of Immunology, vol. 11, no. 1, pp. 40-48, 2014.

[68] J. C. Cyktor, B. Carruthers, R. A. Kominsky, G. L. Beamer, P. Stromberg, and J. Turner, "IL-10 inhibits mature fibrotic granuloma formation during Mycobacterium tuberculosis infection," The Journal of Immunology, vol. 190, no. 6, pp. 2778-2790, 2013.

[69] N. P. Kumar, V. Gopinath, R. Sridhar et al., "IL-10 dependent suppression of type 1 , type 2 and type 17 cytokines in active pulmonary tuberculosis," PLoS ONE, vol. 8, no. 3, Article ID e59572, 2013.

[70] B. Liang, Y. Guo, Y. Li, and H. Kong, "Association between IL-10 gene polymorphisms and susceptibility of tuberculosis: evidence based on a meta-analysis," PLoS ONE, vol. 9, no. 2, Article ID e88448, 2014.

[71] F. W. McNab, J. Ewbank, A. Howes et al., "Type I IFN induces IL-10 production in an IL-27-independent manner and blocks responsiveness to IFN- $\gamma$ for production of IL-12 and bacterial killing in Mycobacterium tuberculosis-infected macrophages," Journal of Immunology, vol. 193, no. 7, pp. 3600-3612, 2014.

[72] P. S. Redford, A. Boonstra, S. Read et al., "Enhanced protection to Mycobacterium tuberculosis infection in IL-10-deficient mice is accompanied by early and enhanced Thl responses in the lung," European Journal of Immunology, vol. 40, no. 8, pp. 2200 2210, 2010.

[73] P. S. Redford, P. J. Murray, and A. O'Garra, "The role of IL-10 in immune regulation during M. tuberculosis infection," Mucosal Immunology, vol. 4, no. 3, pp. 261-270, 2011.

[74] P. Shrivastava and T. Bagchi, "IL-10 modulates in vitro multinucleate giant cell formation in human tuberculosis," PLoS ONE, vol. 8, no. 10, Article ID e77680, 2013.

[75] E.-G. Hong, J. K. Hwi, Y.-R. Cho et al., "Interleukin-10 prevents diet-induced insulin resistance by attenuating macrophage and cytokine response in skeletal muscle," Diabetes, vol. 58, no. 11, pp. 2525-2535, 2009.

[76] M. Straczkowski, I. Kowalska, A. Nikolajuk, A. Krukowska, and M. Gorska, "Plasma interleukin-10 concentration is positively related to insulin sensitivity in young healthy individuals," Diabetes Care, vol. 28, no. 8, pp. 2036-2037, 2005.
[77] E. van Exel, J. Gussekloo, A. J. M. De Craen, M. Frölich, A. B.-V. D. Wiel, and R. G. J. Westendorp, "Low production capacity of interleukin-10 associates with the metabolic syndrome and type 2 diabetes: the Leiden 85-plus study," Diabetes, vol. 51, no. 4, pp. 1088-1092, 2002.

[78] K. Ganeshan and A. Chawla, "Metabolic regulation of immune responses," Annual Review of Immunology, vol. 32, pp. 609-634, 2014.

[79] D. J. Kominsky, E. L. Campbell, and S. P. Colgan, "Metabolic shifts in immunity and inflammation," The Journal of Immunology, vol. 184, no. 8, pp. 4062-4068, 2010.

[80] E. Pearce and E. Pearce, "Metabolic pathways in immune cell activation and quiescence," Immunity, vol. 38, no. 4, pp. 633643, 2013.

[81] M. D. Säemann, G. A. Böhmig, C. H. Osterreicher et al., "Antiinflammatory effects of sodium butyrate on human monocytes: potent inhibition of IL-12 and up-regulation of IL-10 production," The FASEB Journal, vol. 14, no. 15, pp. 2380-2382, 2000.

[82] T. E. Weber and B. J. Kerr, "Butyrate differentially regulates cytokines and proliferation in porcine peripheral blood mononuclear cells," Veterinary Immunology and Immunopathology, vol. 113, no. 1-2, pp. 139-147, 2006.

[83] R. Burcelin, M. Serino, C. Chabo, V. Blasco-Baque, and J. Amar, "Gut microbiota and diabetes: from pathogenesis to therapeutic perspective," Acta Diabetologica, vol. 48, no. 4, pp. 257-273, 2011.

[84] A. M. Caricilli and M. J. A. Saad, "The role of gut microbiota on insulin resistance," Nutrients, vol. 5, no. 3, pp. 829-851, 2013.

[85] B. M. Carvalho and M. J. A. Saad, "Influence of gut microbiota on subclinical inflammation and insulin resistance," Mediators of Inflammation, vol. 2013, Article ID 986734, 13 pages, 2013.

[86] A. Puddu, R. Sanguineti, F. Montecucco, and G. L. Viviani, "Evidence for the gut microbiota short-chain fatty acids as key pathophysiological molecules improving diabetes," Mediators of Inflammation, vol. 2014, Article ID 162021, 9 pages, 2014.

[87] Z. Gao, J. Yin, J. Zhang et al., "Butyrate improves insulin sensitivity and increases energy expenditure in mice," Diabetes, vol. 58, no. 7, pp. 1509-1517, 2009.

[88] H. V. Lin, A. Frassetto, E. J. Kowalik Jr. et al., "Butyrate and propionate protect against diet-induced obesity and regulate gut hormones via free fatty acid receptor 3-independent mechanisms," PLoS ONE, vol. 7, no. 4, Article ID e35240, 2012.

[89] H. Yadav, J.-H. Lee, J. Lloyd, P. Walter, and S. G. Rane, "Beneficial metabolic effects of a probiotic via butyrate-induced GLP-1 hormone secretion," The Journal of Biological Chemistry, vol. 288, no. 35, pp. 25088-25097, 2013.

[90] S. Devaraj, S. K. Venugopal, U. Singh, and I. Jialal, "Hyperglycemia induces monocytic release of interleukin- 6 via induction of protein kinase C- $\alpha$ and $-\beta$," Diabetes, vol. 54 , no. 1 , pp. 85-91, 2005.

[91] C. Sun, L. Sun, H. Ma et al., "The phenotype and functional alterations of macrophages in mice with hyperglycemia for long term," Journal of Cellular Physiology, vol. 227, no. 4, pp. 16701679, 2012.

[92] D. I. Gomez, M. Twahirwa, L. S. Schlesinger, and B. I. Restrepo, "Reduced Mycobacterium tuberculosis association with monocytes from diabetes patients that have poor glucose control," Tuberculosis, vol. 93, no. 2, pp. 192-197, 2013.

[93] J. M. Han, S. J. Patterson, M. Speck, J. A. Ehses, and M. K. Levings, "Insulin inhibits IL-10-mediated regulatory T cell function: implications for obesity," The Journal of Immunology, vol. 192, no. 2, pp. 623-629, 2014. 
[94] A. T. Shamshiev, F. Ampenberger, B. Ernst, L. Rohrer, B. J. Marsland, and M. Kopf, "Dyslipidemia inhibits Toll-like receptorinduced activation of CD8alpha-negative dendritic cells and protective Th1 type immunity," The Journal of Experimental Medicine, vol. 204, no. 2, pp. 441-452, 2007.

[95] K. A. Pyra, D. C. Saha, and R. A. Reimer, "Prebiotic fiber increases hepatic acetyl CoA carboxylase phosphorylation and suppresses glucose-dependent insulinotropic polypeptide secretion more effectively when used with metformin in obese rats," Journal of Nutrition, vol. 142, no. 2, pp. 213-220, 2012.

[96] N.-R. Shin, J.-C. Lee, H.-Y. Lee et al., "An increase in the Akkermansia spp. population induced by metformin treatment improves glucose homeostasis in diet-induced obese mice," Gut, vol. 63, no. 5, pp. 727-735, 2014.

[97] H. A. Hirsch, D. Iliopoulos, and K. Struhl, "Metformin inhibits the inflammatory response associated with cellular transformation and cancer stem cell growth," Proceedings of the National Academy of Sciences of the United States of America, vol. 110, no. 3, pp. 972-977, 2013. 


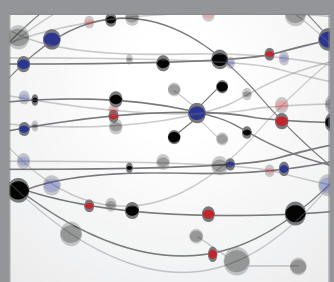

The Scientific World Journal
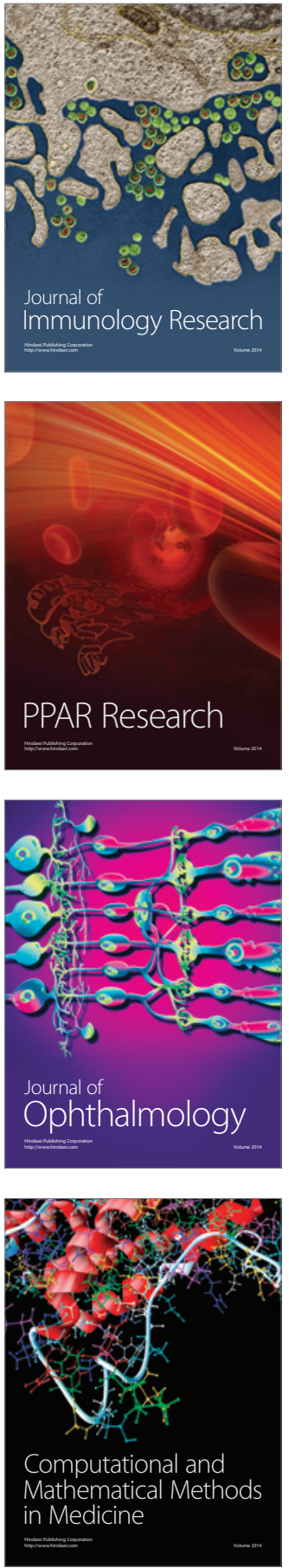

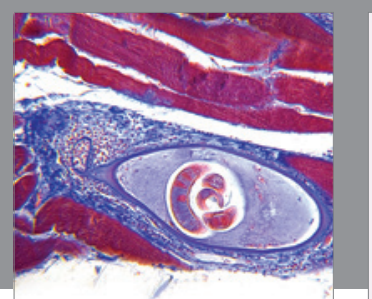

Gastroenterology Research and Practice

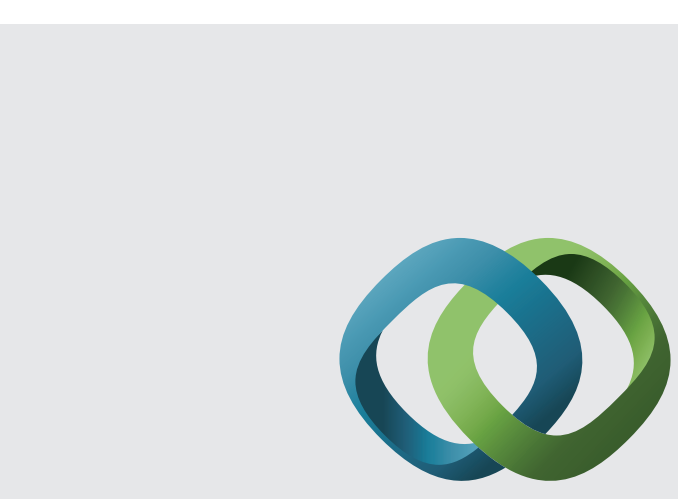

\section{Hindawi}

Submit your manuscripts at

http://www.hindawi.com
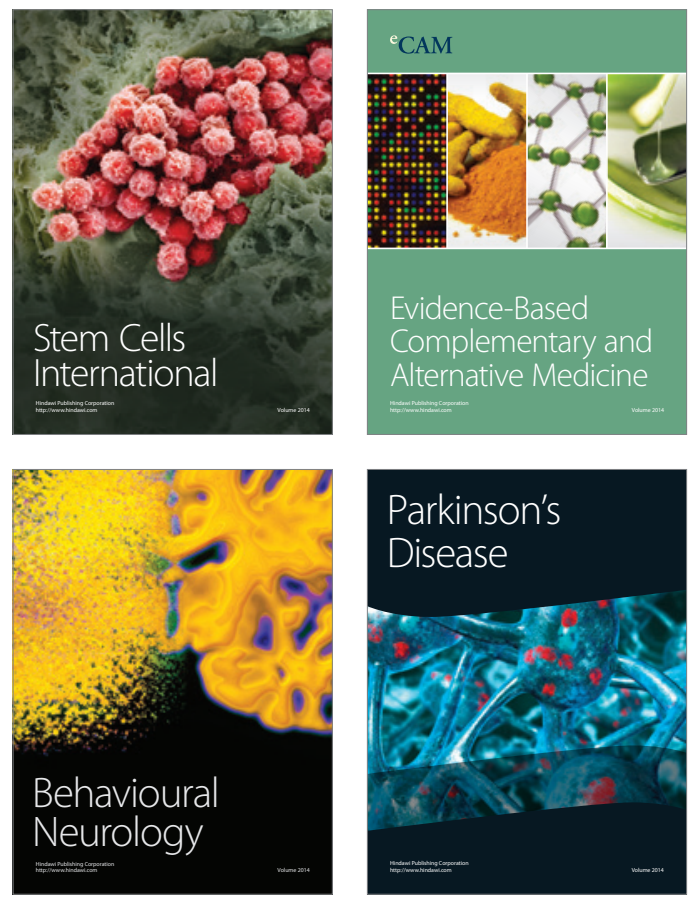
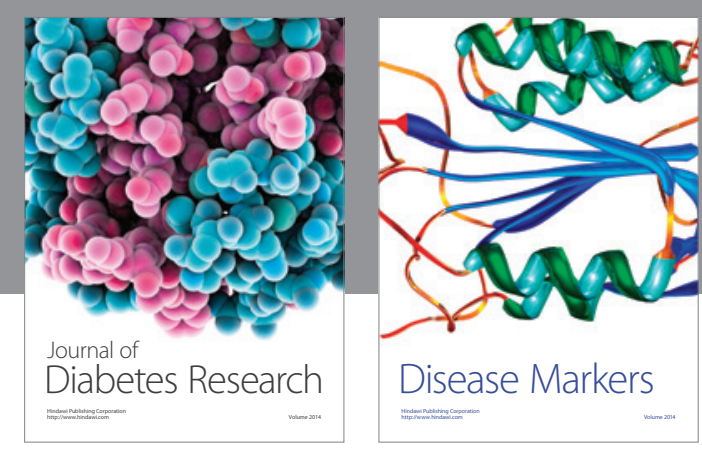

Disease Markers
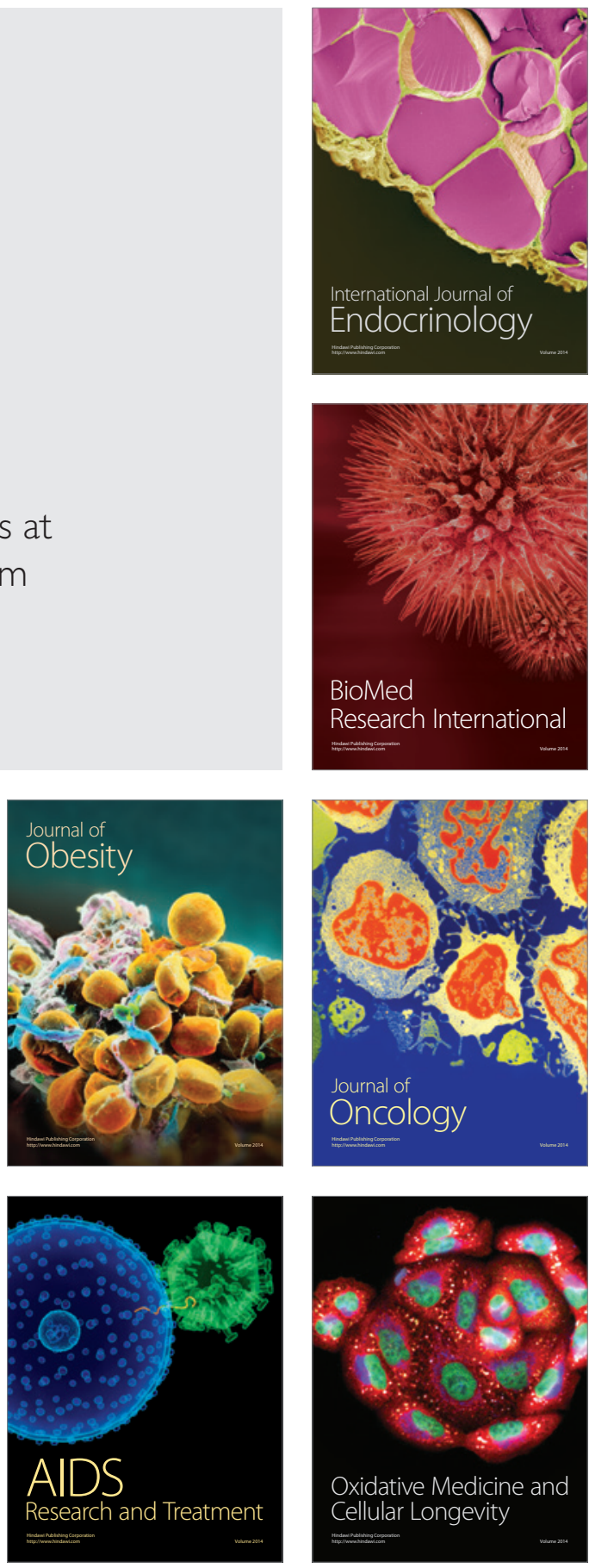